\title{
Artificial Photochemical Devices and Machines
}

\author{
Vincenzo Balzani, Alberto Credi, and Margherita Venturi
}

\section{1 \\ Introduction}

The interaction between light and matter lies at the heart of the most important processes of life [1]. Photons are exploited by natural systems as both quanta of energy and elements of information. Light constitutes an energy source and is consumed (or, more precisely, converted) in large amount in the natural photosynthetic process, whereas it plays the role of a signal in vision-related processes, where the energy used to run the operation is biological in nature.

A variety of functions can also be obtained from the interaction between light and matter in artificial systems [2]. The type and utility of such functions depend on the degree of complexity and organization of the chemical systems that receive and process the photons.

About 20 years ago, in the frame of research on supramolecular chemistry, the idea began to arise [3-5] that the concept of macroscopic device and machine can be transferred to the molecular level. In short, a molecular device can be defined [6] as an assembly of a discrete number of molecular components designed to perform a function under appropriate external stimulation. A molecular machine [6-8] is a particular type of device where the function is achieved through the mechanical movements of its molecular components.

In analogy with their macroscopic counterparts, molecular devices and machines need energy to operate and signal to communicate with the operator. Light provides an answer to this dual requirement. Indeed, a great number of molecular devices and machines are powered by light-induced processes and light can also be useful to "read" the state of the system and thus to control and monitor its operation. Before illustrating examples of artificial photochemical molecular devices and machines, it is worthwhile recalling a few basic aspects of the interaction between molecular and supramolecular systems and light. For a more detailed discussion, books [9-15] can be consulted. 
1.2

\section{Molecular and Supramolecular Photochemistry}

\subsection{1}

\section{Molecular Photochemistry}

Figure 1.1 shows a schematic energy level diagram for a generic molecule that could also be a component of a supramolecular species. In most cases the ground state of a molecule is a singlet state $\left(\mathrm{S}_{0}\right)$ and the excited states are either singlets $\left(\mathrm{S}_{1}, \mathrm{~S}_{2}\right.$, etc.) or triplets $\left(\mathrm{T}_{1}, \mathrm{~T}_{2}\right.$, etc.). In principle, transitions between states having the same spin value are allowed, whereas those between states of different spin are forbidden. Therefore, the electronic absorption bands observed in the UV-visible spectrum of molecules usually correspond to $\mathrm{S}_{0} \rightarrow \mathrm{S}_{n}$ transitions. The excited states so obtained are unstable species that decay by rapid first-order kinetic processes, namely chemical reactions (e.g. dissociation, isomerization) and/or radiative and nonradiative deactivations. In the discussion that follows, excited-state reactions do not need to be explicitly considered and can formally be incorporated within the radiationless decay processes. When a molecule is excited to upper singlet excited states (Figure 1.1), it usually undergoes a rapid and $100 \%$ efficient radiationless deactivation [internal conversion (ic)] to the lowest excited singlet, $\mathrm{S}_{1}$. Such an excited state undergoes deactivation via three competing processes: nonradiative decay to the ground state (internal conversion, rate constant $k_{\text {ic }}$ ); radiative decay to the ground state (fluorescence, $k_{\mathrm{fl}}$ ); conversion to the lowest triplet state $\mathrm{T}_{1}$ (intersystem crossing, $k_{\text {isc }}$ ). In its turn, $\mathrm{T}_{1}$ can undergo deactivation via nonradiative (intersystem crossing, $k_{\text {isc }}^{\prime}$ ) or radiative (phosphorescence, $k_{\mathrm{ph}}$ ) decay to the ground state $\mathrm{S}_{0}$. When the molecule contains heavy atoms, the formally forbidden intersystem crossing and

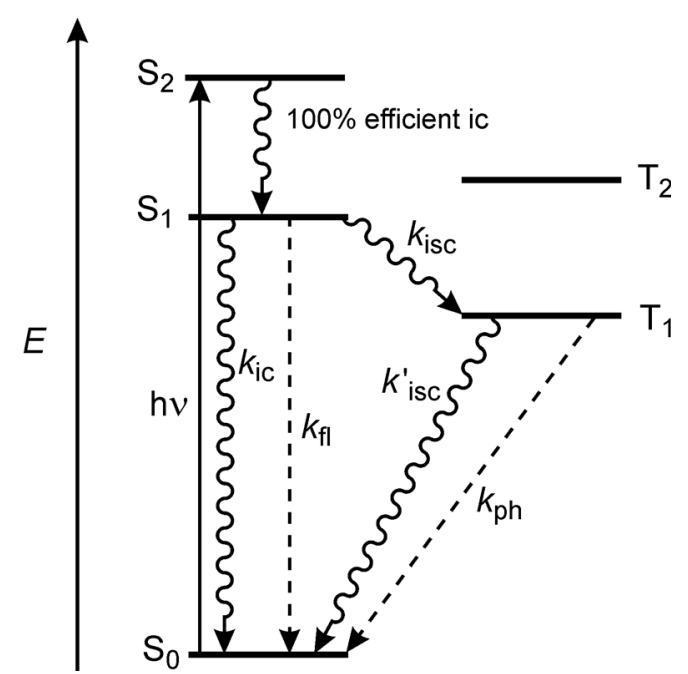

Figure 1.1 Schematic energy level diagram for a generic molecule. For more details, see text. 
phosphorescence processes become faster. The lifetime $(\tau)$ of an excited state, that is, the time needed to reduce the excited-state concentration by 2.718 (i.e. the basis for natural logarithms, e), is given by the reciprocal of the summation of the deactivation rate constants:

$$
\begin{aligned}
\tau\left(\mathrm{S}_{1}\right) & =\frac{1}{\left(k_{\mathrm{ic}}+k_{\mathrm{fl}}+k_{\mathrm{isc}}\right)} \\
\tau\left(\mathrm{T}_{1}\right) & =\frac{1}{\left(k_{\mathrm{isc}}^{\prime}+k_{\mathrm{ph}}\right)}
\end{aligned}
$$

The orders of magnitude of $\tau\left(\mathrm{S}_{1}\right)$ and $\tau\left(\mathrm{T}_{1}\right)$ are approximately $10^{-9}-10^{-7}$ and $10^{-3}-10^{0} \mathrm{~s}$, respectively. The quantum yield of fluorescence (ratio between the number of photons emitted by $S_{1}$ and the number of absorbed photons) and phosphorescence (ratio between the number of photons emitted by $\mathrm{T}_{1}$ and the number of absorbed photons) can range between 0 and 1 and are given by

$$
\begin{aligned}
& \Phi_{\mathrm{fl}}=\frac{k_{\mathrm{fl}}}{\left(k_{\mathrm{ic}}+k_{\mathrm{fl}}+k_{\mathrm{isc}}\right)} \\
& \Phi_{\mathrm{ph}}=\frac{k_{\mathrm{ph}} \times k_{\mathrm{isc}}}{\left(k_{\mathrm{isc}}^{\prime}+k_{\mathrm{ph}}\right) \times\left(k_{\mathrm{ic}}+k_{\mathrm{fl}}+k_{\mathrm{isc}}\right)}
\end{aligned}
$$

Excited-state lifetimes and fluorescence and phosphorescence quantum yields of a great number of molecules are known [16].

When the intramolecular deactivation processes are not too fast, that is, when the lifetime of the excited state is sufficiently long, an excited molecule *A may have a chance to encounter a molecule of another solute, B (Figure 1.2). In such a case, some specific interaction can occur leading to the deactivation of the excited state by second-order kinetic processes. The two most important types of interactions in an encounter are those leading to electron or energy transfer. The occurrence of these processes causes the quenching of the intrinsic properties of ${ }^{*} \mathrm{~A}$; energy transfer also

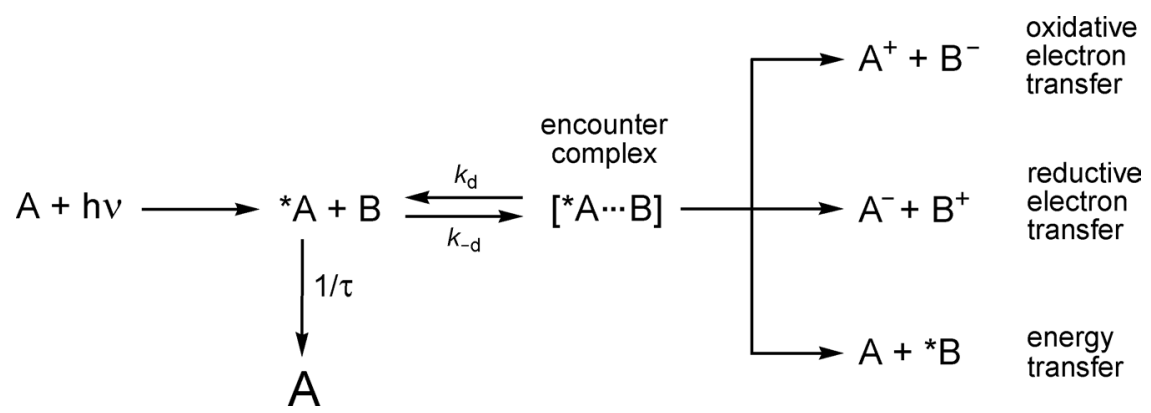

Figure 1.2 Schematic representation of bimolecular electronand energy-transfer processes that may occur following an encounter between an excited state, ${ }^{*} A$, and another chemical species, B. 
leads to sensitization of the excited-state properties of the B species. Simple kinetic arguments show that only the excited states that live longer than ca. $10^{-9} \mathrm{~s}$ may have a chance to be involved in encounters with other solute molecules.

An electronically excited state is a species with completely different properties to those of the ground-state molecule. In particular, because of its higher energy content, an excited state is both a stronger reductant and a stronger oxidant than the corresponding ground state [17]. To a first approximation, the redox potential of an excitedstate couple may be calculated from the potential of the related ground-state couple and the one-electron potential corresponding to the zero-zero excited-state energy, $E^{0-0}$ :

$$
\begin{aligned}
& E\left(\mathrm{~A}^{+} /{ }^{*} \mathrm{~A}\right) \approx E\left(\mathrm{~A}^{+} / \mathrm{A}\right)-E^{0-0} \\
& E\left({ }^{*} \mathrm{~A} / \mathrm{A}^{-}\right) \approx E\left(\mathrm{~A} / \mathrm{A}^{-}\right)+E^{0-0}
\end{aligned}
$$

Detailed discussions of the kinetics aspects of electron- and energy-transfer processes can be found in the literature [11,18-20].

\section{2 .2}

\section{Supramolecular Photochemistry}

A supramolecular system can be preorganized so as to favor the occurrence of electron- and energy-transfer processes [10]. The molecule that has to be excited, A, can indeed be placed in the supramolecular structure nearby a suitable molecule, B.

For simplicity, we consider the case of an A-L-B supramolecular system, where A is the light-absorbing molecular unit [Eq. (7)], B is the other molecular unit involved with $\mathrm{A}$ in the light-induced processes and $\mathrm{L}$ is a connecting unit (often called bridge). In such a system, after light excitation of A there is no need to wait for a diffusioncontrolled encounter between *A and B as in molecular photochemistry, since the two reaction partners can already be at an interaction distance suitable for electron and energy transfer:

$$
\begin{array}{lc}
\mathrm{A}-\mathrm{L}-\mathrm{B}+h v \rightarrow{ }^{*} \mathrm{~A}-\mathrm{L}-\mathrm{B} & \text { photoexcitation } \\
{ }^{*} \mathrm{~A}-\mathrm{L}-\mathrm{B} \rightarrow \mathrm{A}^{+}-\mathrm{L}-\mathrm{B}^{-} & \text {oxidative electron transfer } \\
{ }^{*} \mathrm{~A}-\mathrm{L}-\mathrm{B} \rightarrow \mathrm{A}^{-}-\mathrm{L}-\mathrm{B}^{+} & \text {reductive electron transfer } \\
{ }^{*} \mathrm{~A}-\mathrm{L}-\mathrm{B} \rightarrow \mathrm{A}-\mathrm{L}-{ }^{*} \mathrm{~B} & \text { electronic energy transfer }
\end{array}
$$

In the absence of chemical complications (e.g. fast decomposition of the oxidized and/or reduced species), photoinduced electron-transfer processes [Eqs. (8) and (9)] are followed by spontaneous back-electron-transfer reactions that regenerate the starting ground-state system [Eqs. $8^{\prime}$ and $9^{\prime}$ ] and photoinduced energy transfer [Eq. (10)] is followed by radiative and/or nonradiative deactivation of the excited acceptor [Eq. 10']:

$$
\mathrm{A}^{+}-\mathrm{L}-\mathrm{B}^{-} \rightarrow \mathrm{A}-\mathrm{L}-\mathrm{B} \quad \text { back oxidative electron transfer }
$$




$$
\begin{aligned}
& \mathrm{A}^{-}-\mathrm{L}-\mathrm{B}^{+} \rightarrow \mathrm{A}-\mathrm{L}-\mathrm{B} \quad \text { back reductive electron transfer } \\
& \mathrm{A}-\mathrm{L}-{ }^{*} \mathrm{~B} \rightarrow \mathrm{A}-\mathrm{L}-\mathrm{B} \quad \text { excited state decay }
\end{aligned}
$$

In supramolecular systems, electron- and energy-transfer processes are no longer limited by diffusion and occur by first-order kinetics. As a consequence, in suitably designed supramolecular systems these processes can involve even very short-lived excited states.

\section{3}

\section{Wire-Type Systems}

An important function at the molecular level is photoinduced energy and electron transfer over long distances and/or along predetermined directions. This function can be performed by rod-like supramolecular systems obtained by linking donor and acceptor components with a bridging ligand or a spacer.

\subsection{1}

\section{Molecular Wires for Photoinduced Electron Transfer}

Photoinduced electron transfer in wire-type supramolecular species has been extensively investigated $[6,10]$. The minimum model is a dyad, consisting of an electron donor (or acceptor) chromophore, an additional electron acceptor (or donor) moiety and an organizational principle that controls their distance and electronic interactions (and therefore the rates and yields of electron transfer). A great number of such dyads have been constructed and investigated $[6,10]$.

The energy-level diagram for a dyad is schematized in Figure 1.3. All the dyadtype systems suffer to a greater or lesser extent from rapid charge recombination

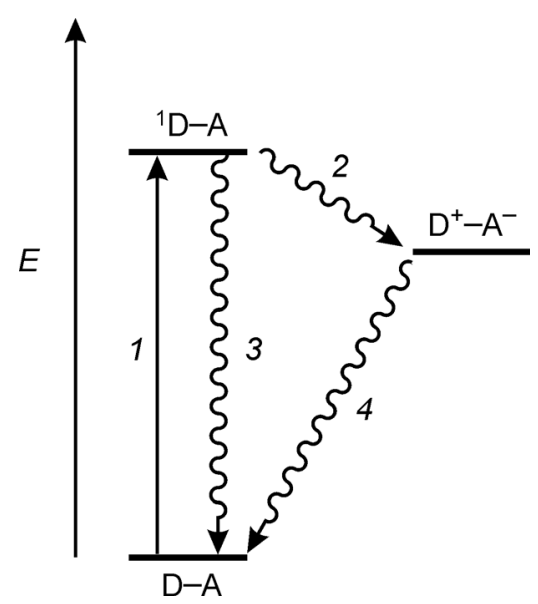

Figure 1.3 Schematic energy-level diagram for a dyad. 
[process (4)]. An example of a systematic study on dyads is that performed on compounds $\mathbf{1}^{5+}-5^{5+}$ (Figure 1.4) [21,22]. When excitation is selectively performed in the $\mathrm{Ru}(\mathrm{II})$ chromophoric unit, prompt intersystem crossing from the originally populated singlet metal-to-ligand charge-transfer $\left({ }^{1} \mathrm{MLCT}\right)$ excited state leads to the long-lived ${ }^{3} \mathrm{MLCT}$ excited state which lies $\sim 2.1 \mathrm{eV}$ above the ground state, can be oxidized approximately at $-0.9 \mathrm{~V}$ (vs. SCE) and has a lifetime of $\sim 1 \mu \mathrm{s}$ in deaerated solutions [23]. Before undergoing deactivation, such an excited state transfers an electron to the $\mathrm{Rh}(\mathrm{III})$ unit, a process that is then followed by a back electron-transfer reaction.

Comparison of compounds $\mathbf{1}^{5+}$ and $2^{5+}$ shows that, despite the longer metalmetal distance, the forward electron transfer is faster across the phenylene spacer $\left(k=3.0 \times 10^{9} \mathrm{~s}^{-1}\right)$ than across the two methylene groups $\left(k=1.7 \times 10^{8} \mathrm{~s}^{-1}\right)$. This result can be related to the lower energy of the LUMO of the phenylene group, which facilitates electronic coupling. In the homogeneous family of compounds $2^{5+}-4^{5+}$, the rate constant decreases exponentially with increasing metal-metal distance.

For compound $5^{5+}$, which is identical with $4^{5+}$ except for the presence of two solubilizing hexyl groups on the central phenylene ring, the photoinduced electrontransfer process is 10 times slower, presumably because the substituents increase the twist angle between the phenylene units, thereby reducing electronic coupling.

Photoinduced electron transfer in three-component systems (triads) is illustrated in Figure 1.5 [24]. The functioning principles are shown in the orbital-type energy diagrams of the lower part the figure. In both cases, excitation of a chromophoric component (step 1) is followed by a primary photoinduced electron transfer to a primary acceptor (step 2). This process is followed by a secondary thermal electrontransfer process (step 3): electron transfer from a donor component to the oxidized chromophoric component (case a) or electron transfer from the primary acceptor to a secondary acceptor component (case b). The primary process competes with excitedstate deactivation (step 4), whereas the secondary process competes with primary charge recombination (step 5). Finally, charge recombination between remote molecular components (step 6) leads the triad back to its initial state.

For case a, the sequence of processes indicated above (1-2-3) is not unique. Actually, the alternative sequence 1-3-2 would also lead to the same charge-separated state. In general, these two pathways will have different driving forces for the primary and secondary steps and thus one may be kinetically favored over the other. Occasionally one of the two pathways is thermodynamically allowed and the other is not, although in a simple one-electron energy diagram like that shown in Figure 1.5a this aspect is not apparent.

The performance of a triad for wire-type applications is related to the rate and quantum yield of formation of the charge separated state (depending on the competition between forward and back processes, $\left.\Phi=\left[k_{2} /\left(k_{2}+k_{4}\right)\right]\left[k_{3} /\left(k_{3}+k_{5}\right)\right]\right)$. For energy conversion purposes, important parameters are also the lifetime of charge separation (depending on the rate of the final charge-recombination process, $\left.\tau=1 / k_{6}\right)$ and the efficiency of energy conversion ( $\eta_{\text {en.conv. }}=\Phi \times F$, where $F$ is the fraction of the excited-state energy conserved in the final charge-separated state). To put things in a real perspective, it should be recalled that the "triad portion" of the 

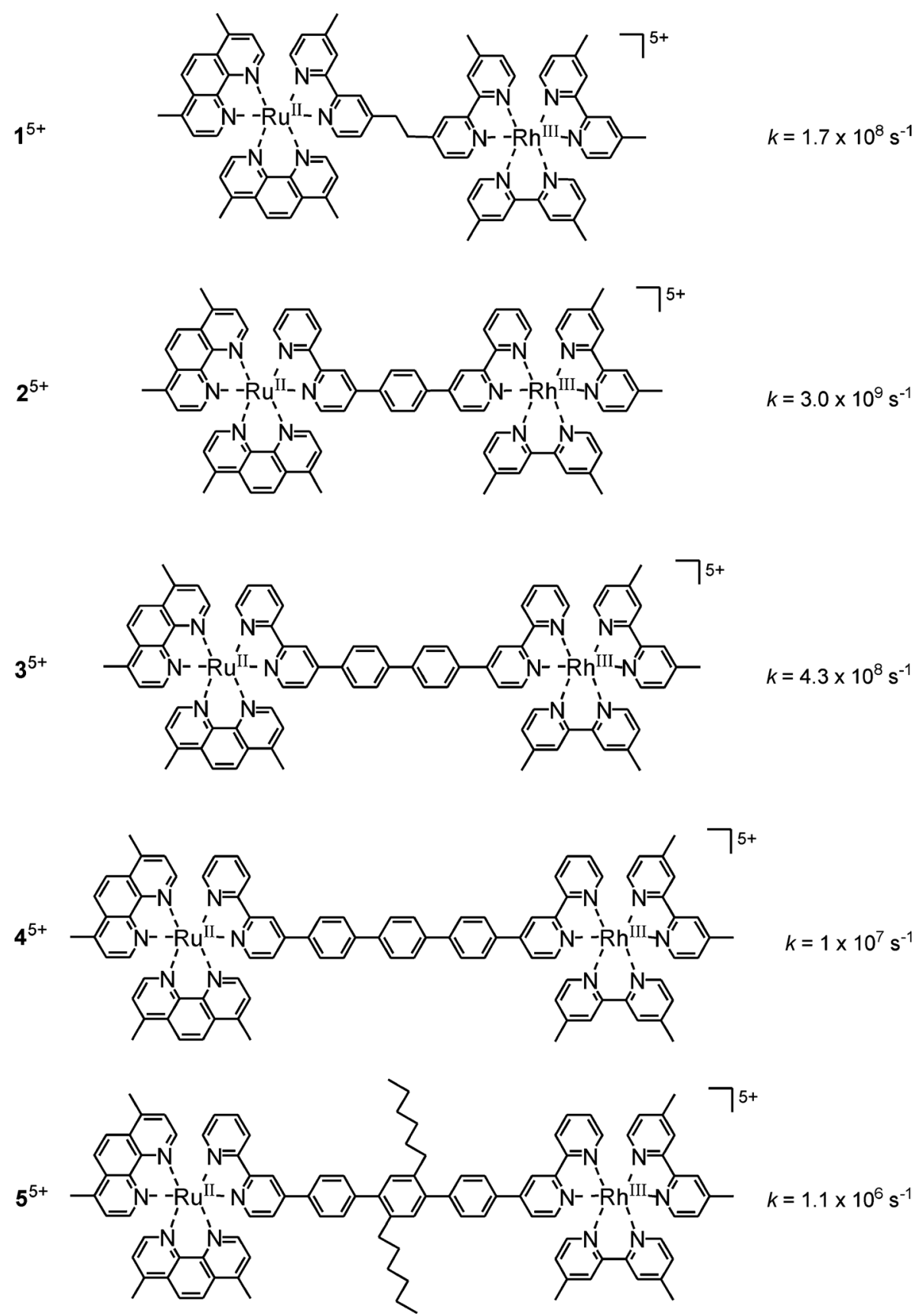

Figure 1.4 Binuclear metal complexes $\mathbf{1}^{5+}-5^{5+}$ used for photoinduced electron-transfer experiments [21,22]. 
8| 1 Artificial Photochemical Devices and Machines

(a)
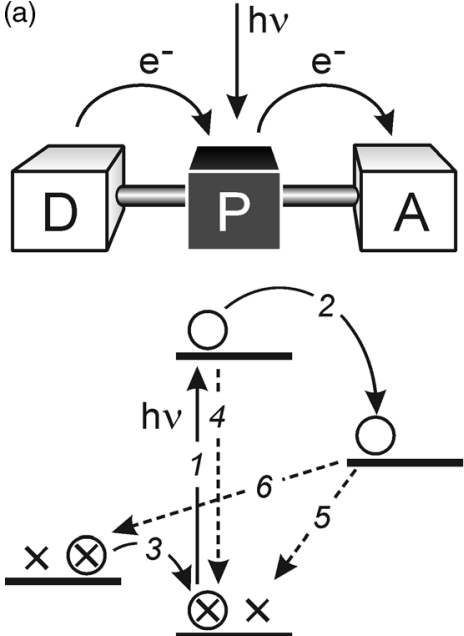

(b)
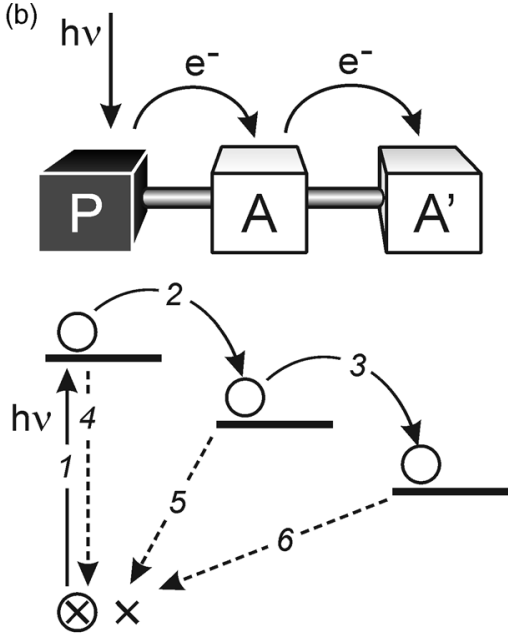

Figure 1.5 Schematic representation of the two possible arrangements for charge-separating triads.

reaction center of bacterial photosynthesis converts light energy with $\tau \approx 10 \mathrm{~ms}$, $\Phi=1$ and $\eta_{\text {en.conv. }} \approx 0.6$.

The introduction of further molecular components (tetrads and pentads) leads to the occurrence of further electron-transfer steps, which, in suitably designed systems, produce charge separation over larger and larger distances [6,10]. As the number of molecular components increases, also the mechanistic complexity increases and charge separation may involve energy-transfer steps.

Several triads have been designed and investigated. A very interesting system is the 4-nm long triad $6^{3+}$ shown in Figure 1.6, which consists of an Ir(III) bis-terpyridine

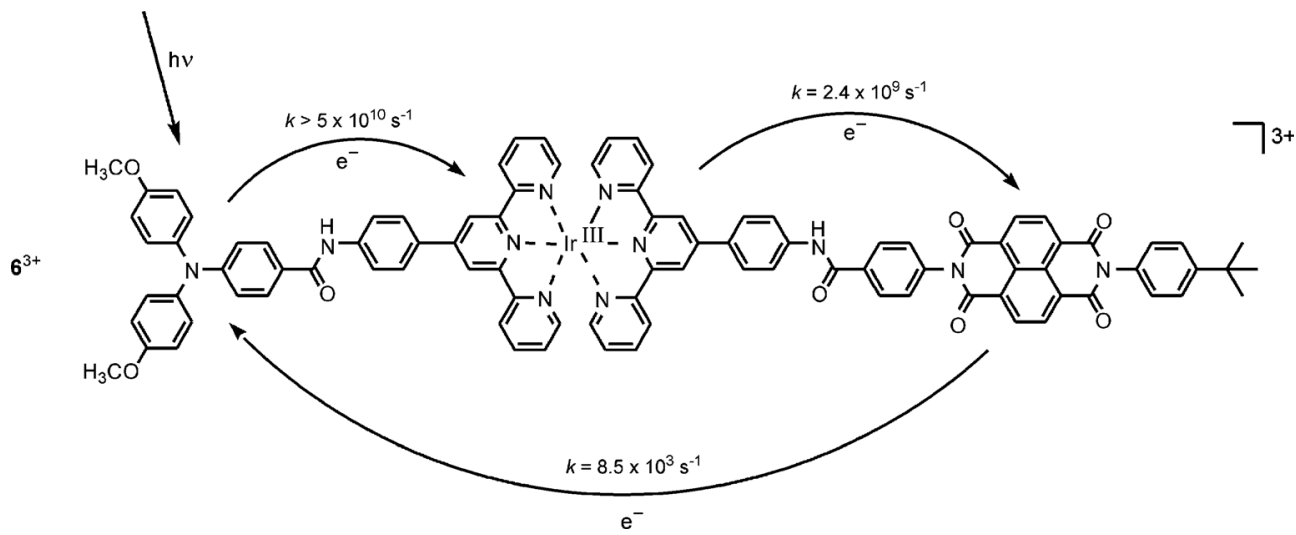

Figure 1.6 Electron-transfer processes in triad $6^{3+}[25]$. 
complex connected to a triphenylamine electron donor (D) and a naphthalene bisimide electron acceptor (A) [25]. Upon excitation of the electron donor D (or even the Ir-based moiety), a charge separated state $\mathrm{D}^{+}-\mathrm{Ir}^{-}-\mathrm{A}$ is formed with $100 \%$ yield in less than 20 ps that successively leads to $\mathrm{D}^{+}-\mathrm{Ir}-\mathrm{A}^{-}$with $10 \%$ efficiency in 400 ps. Remarkably, the fully charge-separated state $\mathrm{D}^{+}-\mathrm{Ir}-\mathrm{A}^{-}$has a lifetime of $120 \mu$ s at room temperature in deaerated acetonitrile solution.

\subsection{2}

\section{Molecular Wires for Photoinduced Energy Transfer}

Many investigations on electronic energy transfer in supramolecular species have been performed in the past few years [6,10], a relevant fraction of which have been obtained for systems containing polypyridine metal complexes as donor and acceptor units. Usually, the photoexcited chromophoric group is $\left[\mathrm{Ru}(\mathrm{bpy})_{3}\right]^{2+}\left(\mathrm{bpy}=2,2^{\prime}\right.$ bipyridine) and the energy acceptor is an $\left[\mathrm{Os}(\mathrm{bpy})_{3}\right]^{2+}$ unit. The excited state of $[\mathrm{Ru}$ $\left.(\text { bpy })_{3}\right]^{2+}$ playing the role of energy donor is the lowest, formally triplet, metal-toligand charge-transfer excited state, ${ }^{3} \mathrm{MLCT}$, which, as we have seen above, can be obtained by visible light excitation $\left(\lambda_{\max } \approx 450 \mathrm{~nm}\right)$, lies $\sim 2.1 \mathrm{eV}$ above the ground state and has a lifetime of $\sim 1 \mu \mathrm{s}$ in deaerated solutions [23]. This relatively long lifetime is very useful because it permits the study of energy transfer over long distances. The occurrence of the energy-transfer process promotes the ground-state $\left[\mathrm{Os}(\mathrm{bpy})_{3}\right]^{2+}$ acceptor unit to its lowest energy excited state ${ }^{3} \mathrm{MLCT}$, which lies approximately $0.35 \mathrm{eV}$ below the donor excited state. Both the donor and the acceptor excited states are luminescent, so that the occurrence of energy transfer can be monitored by quenching and/or sensitization experiments with both continuous and pulsed excitation techniques.

$\mathrm{Ru}(\mathrm{II})$ and $\mathrm{Os}(\mathrm{II})$ polypyridine units have been connected by a variety of bridging ligands and spacers. When the metal-to-metal distance is very short, fast energy transfer occurs by a Förster-type resonance mechanism [26]. In other systems the two photoactive units are separated by a more or less long spacer. When the spacer is flexible [e.g. $-\left(\mathrm{CH}_{2}\right)_{n}-$ chains], the geometry of the system is not well defined and it is difficult to rationalize the results obtained.

These problems are overcome by using rigid and modular spacers to connect the two chromophoric units; the systems so obtained have a well-characterized geometry and the energy transfer can occur over long distances. Interesting examples of this type of systems are the $\left[\mathrm{Ru}(\mathrm{bpy})_{3}\right]^{2+}-(\mathrm{ph})_{n}-\left[\mathrm{Os}(\mathrm{bpy})_{3}\right]^{2+}(\mathrm{ph}=1,4$-phenylene; $n=2$, $3,4,5)$ species [27] shown in Figure 1.7. In such compounds, excitation of the [Ru $\left.(\text { bpy })_{3}\right]^{2+}$ moiety is followed by energy transfer to the $\left[\mathrm{Os}(\mathrm{bpy})_{3}\right]^{2+}$ unit, as shown by the sensitized emission of the latter $\left(\mathrm{CH}_{3} \mathrm{CN}, 293 \mathrm{~K}\right)$. The energy-level diagram is shown schematically in Figure 1.7. The lowest energy level of the bridge decreases slightly as the number of phenylene units is increased, but always lies above the donor and acceptor levels involved in energy transfer. A further decrease in the energy of the triplet excited state of the spacer would be expected to switch the energytransfer mechanism from superexchange-mediated to hopping, similar to what happens for photoinduced electron transfer. In the series of compounds shown in 

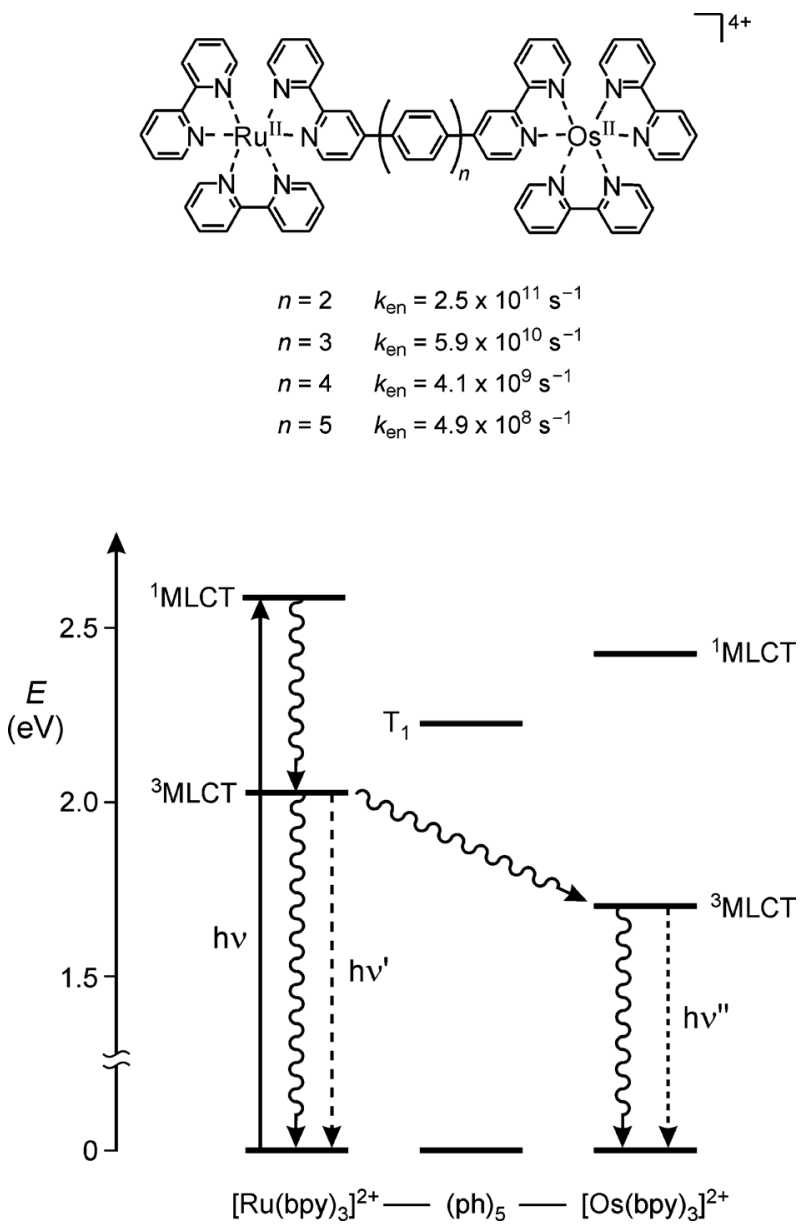

Figure 1.7 Structure of compounds $\left[\mathrm{Ru}(\mathrm{bpy})_{3}\right]^{2+}-(\mathrm{ph})_{n}-\left[\mathrm{Os}(\mathrm{bpy})_{3}\right]^{2+}$ and energy-level diagram for the energy-transfer process [27].

Figure 1.7, the energy-transfer rate decreases with increasing length of the oligophenylene spacer. Such rate constants are much higher than those expected for a Förster-type mechanism, whereas they can be accounted for by a superexchange Dexter mechanism [28]. The values obtained for energy transfer in the analogous series of compounds $\left[\mathrm{Ru}(\mathrm{bpy})_{3}\right]^{2+}-(\mathrm{ph})_{n} \mathrm{R}_{2}-\left[\mathrm{Os}(\mathrm{bpy})_{3}\right]^{2+}[29]$, in which the central phenylene unit carries two hexyl chains, are much lower than those found for the unsubstituted compounds, most likely because the bulky substituents $\mathrm{R}$ increase the tilt angle between the phenyl units. A strong decrease in the rate constant is observed when the Ru-donor and Os-acceptor units are linked via an oligophenylene bridge connected in the meta position [30].

In an another family of similar compounds, $\left[\operatorname{Ir}\left(\mathrm{ppyF}_{2}\right)_{2}(\mathrm{bpy})\right]^{+}-(\mathrm{ph})_{n}-\left[\mathrm{Ru}(\mathrm{bpy})_{3}\right]^{2+}$ (ph =1,4-phenylene; $n=2,3,4,5$ ) [31], the energy-transfer rate constant is much higher and substantially independent of the length of the spacer. The energy-level 


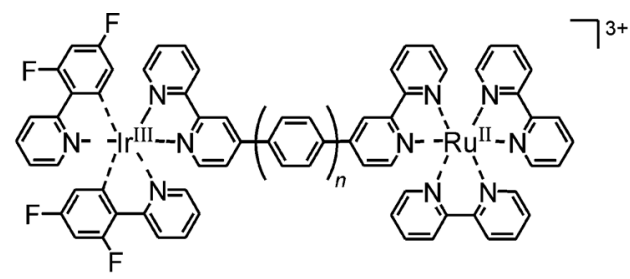

$$
\begin{array}{ll}
n=2 & k_{\mathrm{en}}=8.3 \times 10^{11} \mathrm{~s}^{-1} \\
n=3 & k_{\mathrm{en}}=5.9 \times 10^{11} \mathrm{~s}^{-1} \\
n=4 & k_{\text {en }}=3.6 \times 10^{11} \mathrm{~s}^{-1} \\
n=5 & k_{\text {en }}=3.3 \times 10^{11} \mathrm{~s}^{-1}
\end{array}
$$

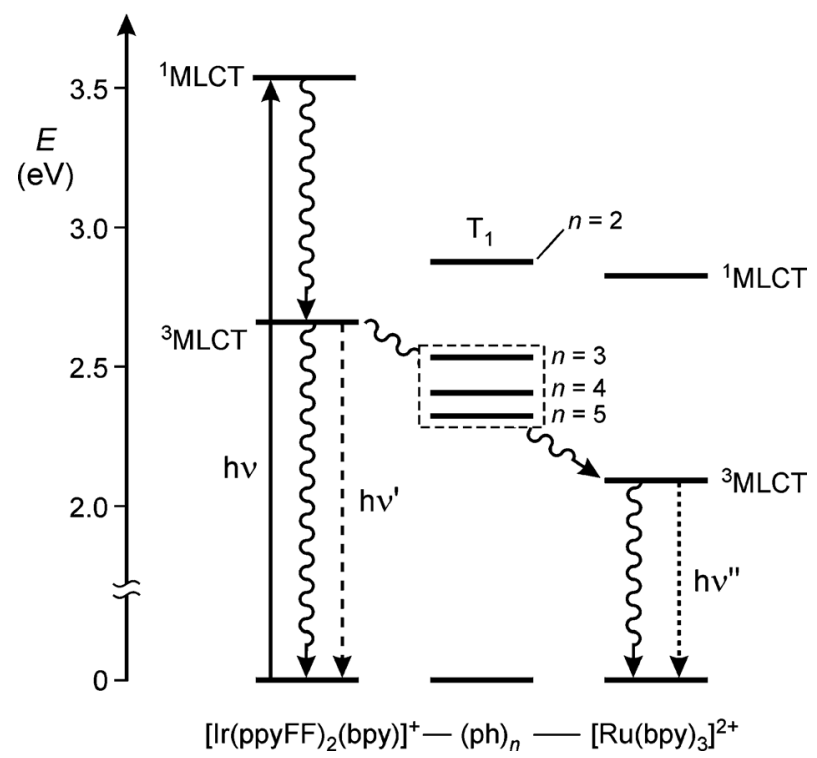

Figure 1.8 Structure of compounds $\left[\operatorname{lr}\left(\mathrm{ppyF}_{2}\right)_{2}(\mathrm{bpy})\right]^{+}-(\mathrm{ph})_{n^{-}}$ $\left[\mathrm{Ru}(\mathrm{bpy})_{3}\right]^{2+}$ and energy-level diagram for the energy-transfer process [31].

diagram for this family, displayed in Figure 1.8, shows that the energy level of the donor is almost isoenergetic with the triplet state of the spacers. The energy of the Irbased donor can, therefore, be transferred to the Ru-based acceptor via hopping on the bridging ligand, at least for $n>2$.

\section{4}

\section{Switching Electron-Transfer Processes in Wire-Type Systems}

A clever choice of molecular components and their assembly in suitable sequences allow the design of very interesting molecular-level photonic switches for photoinduced electron-transfer processes. 

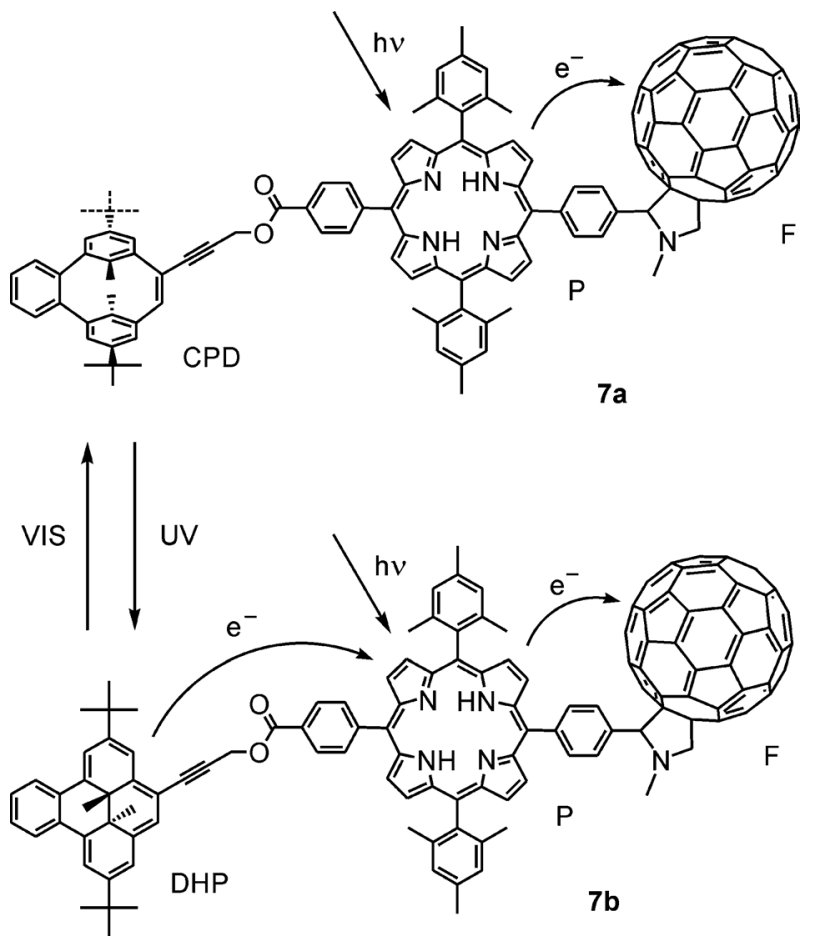

Figure 1.9 A single pole electron-transfer switch. Light-induced isomerization and electron transfer processes in triad 7 [32].

Triad 7 (Figure 1.9) is an example of electron transfer switch generated by the lightinduced interconversion between the two forms of a chromophore. This triad, which performs as a single pole molecular switch, consists of a porphyrin unit $(\mathrm{P})$ linked covalently to both a fullerene $(F)$ electron acceptor and a dihydropyrene photochrome [32]. In structure 7a, the photochrome is in the cyclophanediene (CPD) form, which absorbs light only in the UV region. Excitation of the porphyrin unit leads to $\mathrm{CPD}-{ }^{1} \mathrm{P}-\mathrm{F}$ excited state which undergoes electron transfer yielding the $\mathrm{CPD}-\mathrm{P}^{+}-\mathrm{F}^{-}$charge-separated state with unitary efficiency. Such a state then decays to the ground state with time constant $3.3 \mathrm{~ns}$. Irradiation of 7a with UV light at $254 \mathrm{~nm}$ converts the cyclophanediene form of the photochrome into the dihydropyrene form (DHP). The photochemistry of the resulting DHP-P-F species (7b) is different from that of $7 \mathrm{a}$. The $\mathrm{DHP}-{ }^{1} \mathrm{P}-\mathrm{F}$ excited state leads again to charge separation, DHP $-\mathrm{P}^{+}-\mathrm{F}^{-}$, but before the charge separated state can recombine to the ground state, an electron migrates from the DHP moiety to the porphyrin, producing $\mathrm{DHP}^{+}-\mathrm{P}-\mathrm{F}^{-}$with quantum yield 0.94 . This state lives much longer $(2.0 \mu \mathrm{s})$ than the CPD- $\mathrm{P}^{+}-\mathrm{F}^{-}$species because the charges are much farther apart and, therefore, the electronic coupling is smaller. Reconfiguration of the system to 7a can be obtained by visible light irradiation. 


\section{5}

\section{A Plug-Socket Device Based on a Pseudorotaxane}

Supramolecular species whose components are connected by means of noncovalent forces can be disassembled and re-assembled [33] by modulating the interactions that keep the components together, with the consequent possibility of switching energytransfer processes. Two-component systems of this type are reminiscent of plugsocket electrical devices because, like their macroscopic counterparts, they are characterized by (i) the possibility of connecting-disconnecting the two components in a reversible way and (ii) the occurrence of an electronic energy flow from the socket to the plug when the two components are connected (Figure 1.10a). Hydrogenbonding interactions between ammonium ions and crown ethers are particularly

(a)

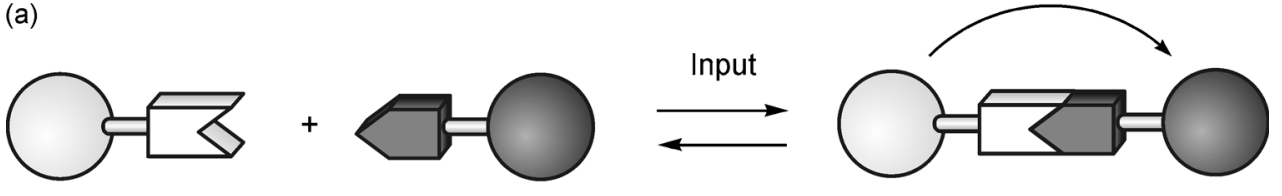

(b)

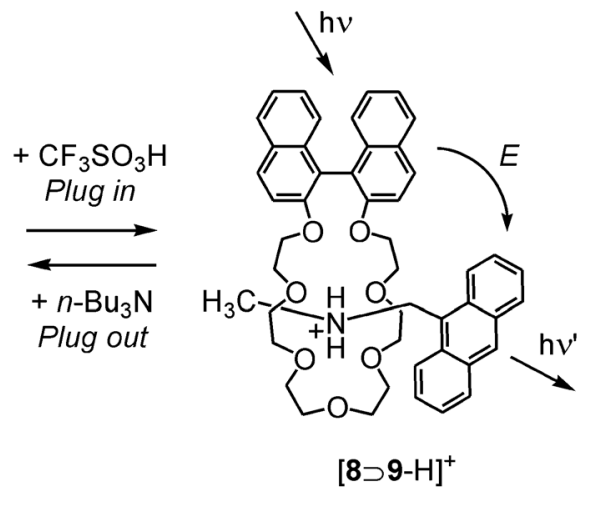

8

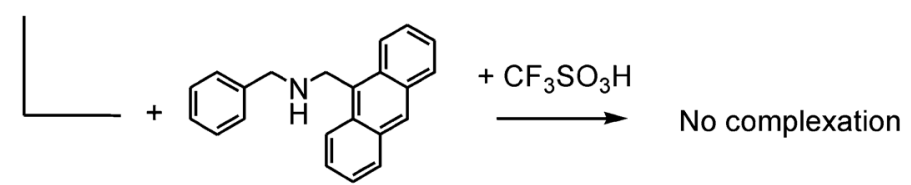

10

Figure 1.10 (a) Schematic representation of the working mechanism of a plug-socket system. (b) Switching of photoinduced energy transfer by the acid-base-controlled plug in-plug out of binaphthocrown ether 8 and anthracenylammonium ion $\mathbf{9}-\mathrm{H}^{+}[34]$. 
suitable for constructing molecular-level plug-socket devices, since they can be switched on and off quickly and reversibly by means of acid-base inputs.

A plug-socket system which deals with the transfer of electronic energy is illustrated in Figure 1.10b [34]. The absorption and fluorescence spectra of a $\mathrm{CH}_{2} \mathrm{Cl}_{2}$ solution containing equal amounts of $( \pm$ )-binaphthocrown ether 8 and amine 9 indicate the absence of any interaction between the two compounds. Addition of a stoichiometric amount of acid, capable of protonating 9 , causes profound changes in the fluorescence behavior of the solution, namely (i) the fluorescence of 8 is completely quenched and (ii) the fluorescence of $9-\mathrm{H}^{+}$is sensitized upon excitation with light absorbed exclusively by the crown ether. These observations are consistent with the formation of an adduct between 8 and $9-\mathrm{H}^{+}$, wherein very efficient electronic energy transfer occurs from the photoexcited binaphthyl unit of the crown ether to the anthracenyl group incorporated within the $\mathbf{9}-\mathrm{H}^{+}$component. Such an adduct belongs to the class of pseudorotaxanes, that is, supermolecules made (at the minimum) of a thread-like guest molecule surrounded by a macrocyclic host, because dialkylammonium ions are known [35] to penetrate the cavity of crown ethers such as 8 . The very fast rate constant $\left(k>4 \times 10^{9} \mathrm{~s}^{-1}\right)$ for the energy-transfer process [34] can be accounted for by a coulombic mechanism, as molecular models show that the maximum distance between binaphthyl and anthracene units in the $8 \supset$ 9- $\mathrm{H}^{+}$complex $(\sim 15 \AA)$ is much shorter than their Förster radius $(26 \AA)$.

The pseudorotaxane $8 \supset \mathbf{9}-\mathrm{H}^{+}$can be disassembled by the subsequent addition of a stoichiometric amount of base, capable of deprotonating $9-\mathrm{H}^{+}$, thereby interrupting the photoinduced energy flow, as indicated by the restoring of the initial absorption and fluorescence spectra. Moreover, the stability of this pseudorotaxane can be influenced by changing the nature of the counteranion of $9-\mathrm{H}^{+}$[36]. Interestingly, the plug-in process does not occur when a plug component incompatible with the size of the socket, such as the benzyl-substituted amine 10, is employed (Figure 1.10b).

\section{6}

\section{Mimicking Electrical Extension Cables at the Molecular Level}

The plug-socket concept described above can be used to design molecular systems which mimic the function played by a macroscopic electrical extension cable. The operation of an extension cable is more complex than that of a plug-socket system, because it involves three components that must be held together by two connections that have to be controllable reversibly and independently, in the fully connected system, an electron or energy flow must take place between the remote donor and acceptor units (Figure 1.11).

In the attempt to construct a molecular-level extension cable for electron transfer, the pseudorotaxane shown in Figure 1.12a, made of the three components $11^{2+}$, 12- $\mathrm{H}^{3+}$ and 13 , has been obtained and studied [37]. Component $11^{2+}$ consists of two moieties: an $\left[\mathrm{Ru}(\mathrm{bpy})_{3}\right]^{2+}$ unit, which behaves as an electron donor under light excitation, and a dibenzo[24]crown-8 macrocycle, capable of playing the role of a hydrogen-bonding first socket. The dialkylammonium-based moiety of $12-\mathrm{H}^{3+}$, 


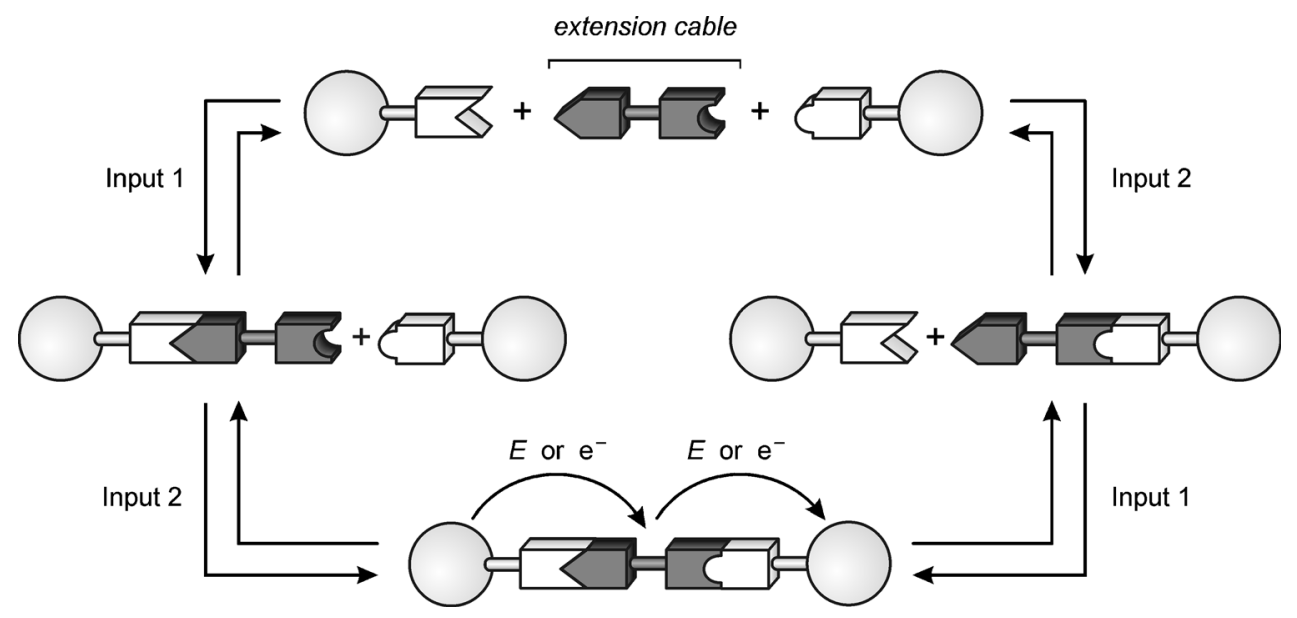

Figure 1.11 (a) Schematic representation of the working mechanism of an electrical extension cable.

driven by hydrogen-bonding interactions, threads as a plug into the first socket, whereas the $\pi$-electron accepting 4,4'-bipyridinium unit threads as a plug into the third component 13, the $\pi$-electron rich 1,5-dinaphtho[38]crown-10 macrocycle, which plays the role of a second socket. In $\mathrm{CH}_{2} \mathrm{Cl}_{2}-\mathrm{CH}_{3} \mathrm{CN}(98: 2 \mathrm{v} / \mathrm{v})$ solution, reversible connection-disconnection of the two plug-socket junctions can be controlled independently by acid-base and redox stimulation, respectively, and monitored by changes in the absorption and emission spectra, owing to the different nature of the interactions (hydrogen bonding and $\pi$-electron donor-acceptor) that connect the components. In the fully assembled triad, $11^{2+} \supset 12-\mathrm{H}^{3+} \subset 13$, light excitation of the $\left[\mathrm{Ru}(\mathrm{bpy})_{3}\right]^{2+}$ unit of the component $11^{2+}$ is followed by electron transfer to the bipyridinium unit of the component $12-\mathrm{H}^{3+}$, which is plugged into component 13.

It should be noted that in the system described above, the transferred electron does not reach the final component of the assembly. Moreover, a true extension cable should contain a plug and a socket at the two ends, instead of two plugs as component 12- $\mathrm{H}^{3+}$. An improved system of that type has been investigated recently (Figure 1.12b) [38]. The electron-source component is again $\mathbf{1 1}^{2+}$, whereas the new extension cable 14- $\mathrm{H}^{+}$is made up [39] of a dialkylammonium ion, that can insert itself as a plug into a dibenzo [24]crown-8 socket, a biphenyl spacer and a benzonaphtho [36] crown-10 unit, which fulfills the role of a $\pi$-electron-rich socket. Finally, the $1,1^{\prime}$-dioctyl-4,4'bipyridinium dication $15^{2+}$ can play the role of an electron drain plug. As for the previously studied system, the two plug-socket connections $11^{2+} \supset 14-\mathrm{H}^{+}$and $14-\mathrm{H}^{+}$ $\supset 15^{2+}$ can be controlled by acid-base and redox stimuli, respectively.

In the complete ensemble, $11^{2+} \supset 14-\mathrm{H}^{+} \supset 15^{2+}$, light excitation of the Ru-based unit of $11^{2+}$ is followed by electron transfer to $15^{2+}$, with $14-\mathrm{H}^{+}$playing the role of an extension cable (Figure 1.12b). The occurrence of this process is confirmed by nanosecond laser flash photolysis experiments, showing a transient absorption 
16| 1 Artificial Photochemical Devices and Machines

(a)
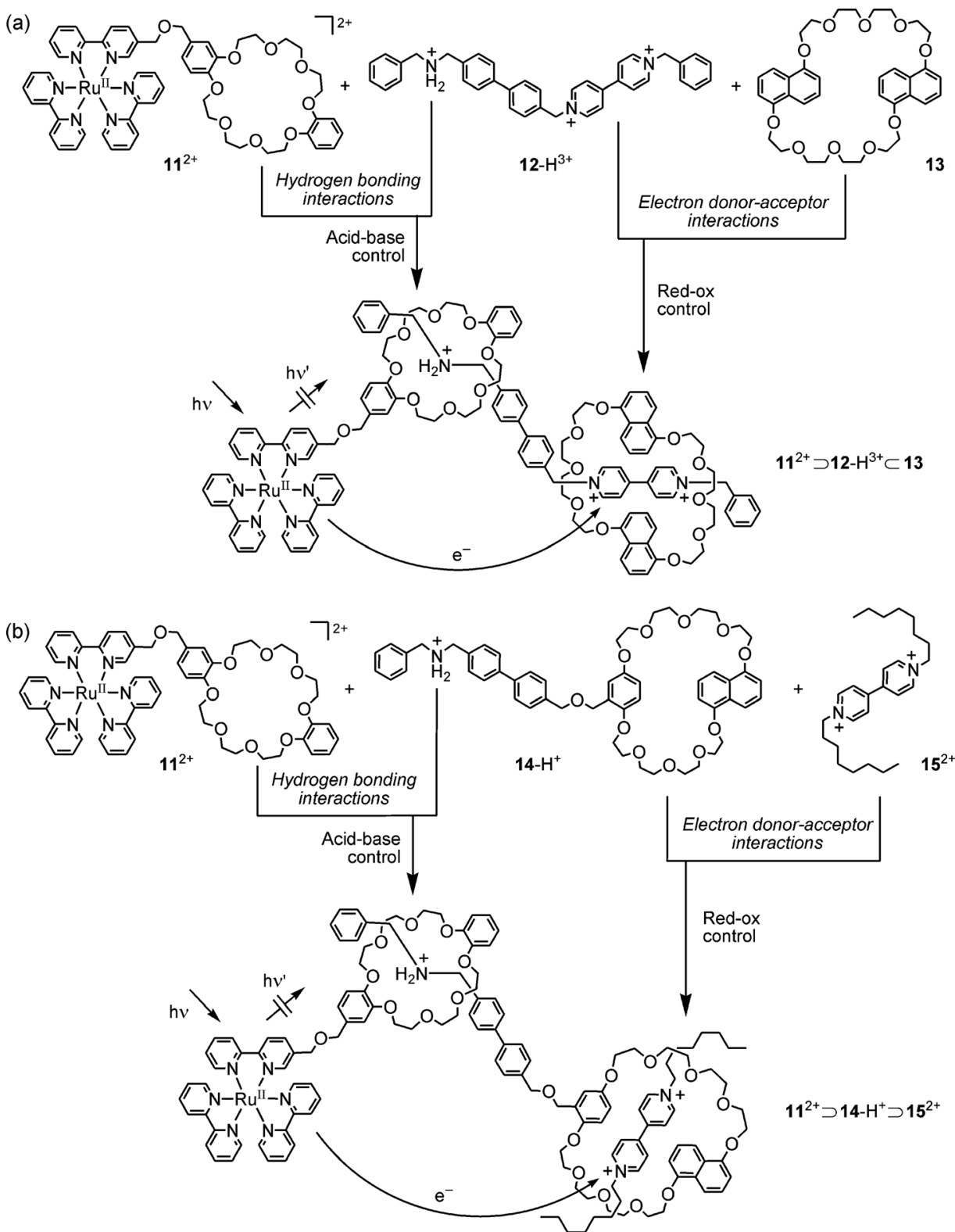

Figure 1.12 First- and second-generation systems for mimicking an electrical extension cable. (a) Structural formulas of the three molecular components $11^{2+}, 12-\mathrm{H}^{+}$and $\mathbf{1 3}$, which self-assemble in solution to give the $11^{2+} \supset 12-\mathrm{H}^{3+} \supset 13$ triad. The photoinduced electron-transfer process from the Ru-based unit transfer to $15^{2+}$, with $14-\mathrm{H}^{+}$playing the role of an of $11^{2+}$ to the bipyridinium unit of $12-\mathrm{H}^{3+}$ taking extension cable [38].

place in the fully connected system is

also represented [37]. (b) Structural formulas of the three molecular components $11^{2+}, 14-\mathrm{H}^{+}$ and $15^{2+}$, which self-assemble in solution to give the $11^{2+} \supset 14-\mathrm{H}^{+} \supset 15^{2+}$ triad. In the fully connected system, excitation with visible light of the Ru-based unit of $11^{2+}$ is followed by electron 
signal assigned to the 4,4'-bipyridinium radical cation formed by photoinduced electron transfer within the self-assembled triad. Such a second-generation system exhibits two conceptual and significant advancements: (i) $14-\mathrm{H}^{+}$consists of a plug and a socket components and thus it really mimics an extension cable; (ii) the photoinduced electron transfer does occur from the first component - the Ru-based unit of $11^{2+}$ - to the remote $15^{2+}$ moiety, whereas in the previous system the electron receiving bipyridinium unit was a component of the cable.

\section{7}

\section{Light-Harvesting Antennas}

An antenna for light harvesting (Figure 1.13) is an organized multicomponent system in which several chromophoric molecular species absorb the incident light and channel the excitation energy to a common acceptor component [40]. For artificial systems, the term "antenna effect" was first used [41] to discuss the case of strongly emitting but weakly absorbing lanthanide ions surrounded by strongly absorbing ligands, where the luminescence of the lanthanide ion was sensitized by excitation in the ligand-centered excited states. Research in this area is still very active [42]. Antenna systems are widely used by Nature to solve the problem of lightharvesting efficiency in the photosynthetic process where light is converted into chemical energy [43]. Collecting light by an antenna system, however, may also be useful for other purposes, such as signal amplification in luminescence sensors [44], photodynamic cancer therapy [45] and up-conversion processes [46]. A large system, where an array of chromophoric units absorb light and transfer energy to a luminescent center, can also be considered a spatial and spectral energy concentrator (“molecular lens") [47].

The antenna effect can only be obtained in supramolecular arrays suitably organized in the dimensions of time, energy and space. Each molecular component has to absorb the incident light and the excited state so obtained (donor) has to transfer electronic energy to a nearby component (acceptor), before undergoing radiative or nonradiative deactivation (organization in the time dimension). In order

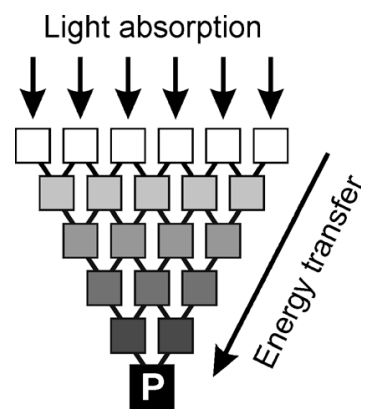

Figure 1.13 Schematic representation of a light-harvesting antenna system. Squares represent light-absorbing molecules. $P$ is the molecule to which excitation energy is channeled. Excited state energy decreases with increasing shade. 
for energy transfer to occur, the energy of the acceptor excited state has to be lower or, at most, equal to the energy of the excited state of the donor (organization in the energy dimension). Finally, the successive donor-to-acceptor energy-transfer steps must result in an overall energy-transfer process leading the excitation energy towards a selected component of the array (organization in the space dimension).

In the course of evolution, Nature has succeeded to build up antenna systems that fully satisfy the above requirements. In green plants, such natural antennae collect an enormous amount of solar energy and redirect it as electronic excitation energy to reaction centers where subsequent conversion into redox chemical energy takes place. In recent years, the development of supramolecular chemistry (particularly of dendrimer chemistry) and the high level of experimental and theoretical efficacy reached by photochemistry have enabled scientists to design and construct a number of interesting artificial antenna systems.

Dendrimer $\mathbf{1 6}^{2+}$ (Figure 1.14) is a classical example of antenna system [48]. The $2,2^{\prime}$-bipyridine ligands of the $\left[\mathrm{Ru}(\mathrm{bpy})_{3}\right]^{2+}$-type [49] core carry branches containing

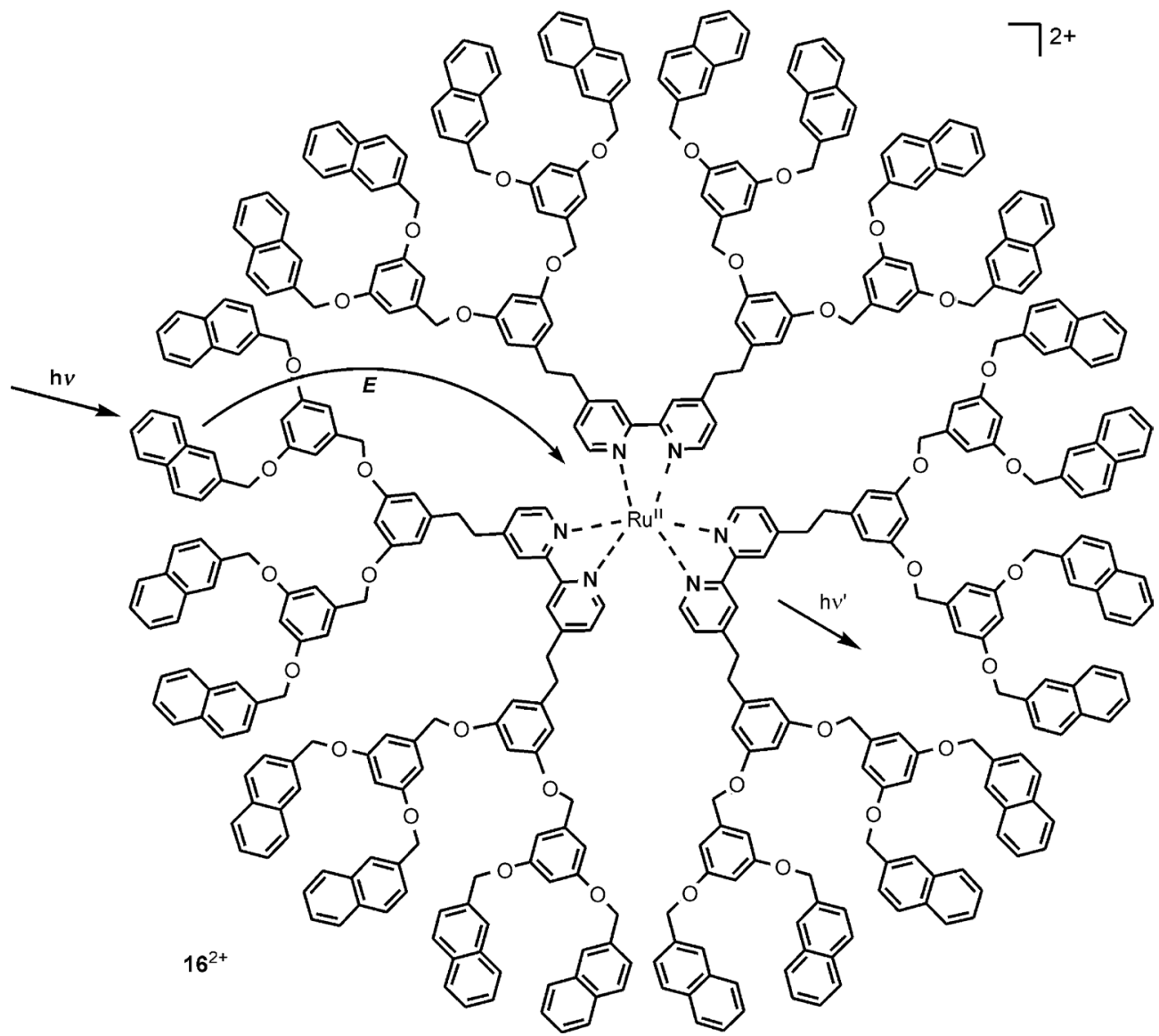

Figure 1.14 Antenna effect in dendrimer $16^{2+}$ with $\left[\mathrm{Ru}(\mathrm{bpy})_{3}\right]^{2+}$ core [48]. 
1,2-dimethoxybenzene- and 2-naphthyl-type chromophoric units. Because such units (as well as the core) are separated by aliphatic connections, the interchromophoric interactions are weak and the absorption spectrum of the dendrimer is substantially equal to the summation of the spectra of the chromophoric groups that are present in its structures. The three types of chromophoric groups, namely, $\left[R u(b p y)_{3}\right]^{2+}$, dimethoxybenzene and naphthalene, are potentially luminescent species. In the dendrimer, however, the fluorescence of the dimethoxybenzene- and naphthyl-type units is almost completely quenched in acetonitrile solution, with concomitant sensitization of the luminescence of the $\left[\mathrm{Ru}(\mathrm{bpy})_{3}\right]^{2+}$ core $\left(\lambda_{\max }=610 \mathrm{~nm}\right)$. These results show that a very efficient energy-transfer process takes place converting the very short-lived (nanosecond time-scale) UV fluorescence of the aromatic units of the wedges to the long-lived (microsecond time-scale) orange emission of the metalbased dendritic core. It should also be noted that in aerated solution the luminescence intensity of the dendrimer core is more than twice as intense as that of the $\left[\mathrm{Ru}(\mathrm{bpy})_{3}\right]^{2+}$ parent compound because the dendrimer branches protect the Ru-bpy based core from dioxygen quenching [50]. In conclusion, because of the very high absorbance of the naphthyl groups in the UV spectral region, the high energy-transfer efficiency and the strong emission of the $\left[\mathrm{Ru}(\mathrm{bpy})_{3}\right]^{2+}$-type core, dendrimer $1 \mathbf{6}^{2+}$ (Figure 1.14) exhibits a strong visible emission upon UV excitation even in very dilute $\left(10^{-7} \mathrm{~mol} \mathrm{~L}^{-1}\right)$ solutions [48].

\section{8}

\section{Artificial Molecular Machines}

\subsection{1}

\section{Introduction}

Natural molecular-level machines and motors are extremely complex systems. Any attempt to construct systems of such complexity by using an artificial bottom-up molecular approach would be hopeless. In the field of artificial systems, we can only construct simple prototypes consisting of a few molecular components, but we can use a chemical toolbox much larger than that used by Nature, exploit innovative ideas and operate in a much wider range of conditions (particularly as far as energy supply is concerned).

It designing artificial molecular devices, it should be recalled that they cannot be "shrunk" versions of macroscopic counterparts, because the operational mechanisms of motion at the molecular level have to deal with phenomena different from those that govern the macroscopic world [51,52]. Gravity and inertia motions that we are familiar with in our everyday experience are negligible at the molecular scale, where the viscous forces resulting from intermolecular interactions (including those with solvent molecules) largely prevail. This means that although we can describe the bottom-up construction of a nanoscale device as an assembly of suitable (molecular) components by analogy with what happens in the macroscopic world, we should not forget that the design principles and the operating mechanisms at the molecular level are different. 
Mechanical movements at the molecular level result from nuclear motions caused by chemical reactions. Any kind of chemical reaction involves, of course, some nuclear displacement, but only large-amplitude, nontrivial motions leading to real translocation of some component parts of the system are considered. Particularly interesting nuclear motions from the viewpoint of artificial molecular systems are those related to (i) isomerization reactions involving $-\mathrm{N}=\mathrm{N}-,-\mathrm{C}=\mathrm{N}-$ and $-\mathrm{C}=\mathrm{C}$ - double bonds in covalent supramolecular structures, (ii) acid-base or redox reactions causing making or breaking of intermolecular bonds (including hydrogen bonds) and (iii) metal-ligand reactions causing the formation or disruption of coordination bonds.

Like macroscopic systems, mechanical molecular-level systems are characterized by: (a) the kind of energy supplied to make them work; (b) the kind of movement performed by their components; (c) the way in which their operation can be controlled and monitored; (d) the possibility of repeating the operation at will; (e) the time-scale needed to complete a cycle of operation; and (f) the function performed. Particularly interesting is the way in which energy can be supplied.

\section{8 .2}

\section{Energy Supply}

To make a molecular machine move, energy must be supplied. The most obvious way of supplying energy to a chemical system is by adding a reactant (fuel) capable of causing a desired reaction. In his famous address "There is Plenty of Room at the Bottom" to the American Physical Society, R.P. Feynman discussed the possibility of constructing molecular-level machines and observed [53]: "An internal combustion engine of molecular size is impossible. Other chemical reactions, liberating energy when cold, can be used instead". This is exactly what happens in our body, in which the chemical energy, ultimately derived from food and oxygen, is used in a long series of slightly exoergonic reactions to power the biological machines that sustain life.

If an artificial molecular-level machine must work by inputs of chemical energy, it will need addition of fresh reactants ("fuel") at any step of its working cycle [54]. It should be noticed that even cycling between two forms of a molecular-level system under the action of chemical inputs implies formation of waste products. For example, if the forward reaction is caused by an acid input, successive addition of a base will return the system to its original form, but the acid-base reaction generates waste products. Accumulation of waste products will inevitably compromise the operation of the machine, unless they are removed from the system, as happens both in natural machines and in macroscopic internal combustion engines.

The need to remove waste products introduces noticeable limitations in the design and construction of artificial molecular machines and motors based on "chemical fuel” inputs [55]. All the proposed systems operating by use of chemical energy become increasingly less efficient on increasing the number of cycles and finally stop working. 
There are, however, alternative, more convenient, ways of powering artificial molecular machines.

\subsection{3}

\section{Light Energy}

In green plants the energy needed to sustain the machinery of life is provided by sunlight [43]; in general, light energy is not used as such to produce mechanical movements, but it is used to produce a chemical fuel, namely ATP, suitable for feeding natural molecular machines. Light energy, however, can directly cause photochemical reactions involving large nuclear movements. A simple example is a photoinduced isomerization from the lower energy trans to the higher energy cis form of a molecule containing $-\mathrm{C}=\mathrm{C}-$ or $-\mathrm{N}=\mathrm{N}-$ double bonds; this is followed by a spontaneous or light-induced back reaction $[9,10]$. Such photoisomerization reactions have indeed been used to make molecular machines driven by light energy inputs [56]. In supramolecular species, photoinduced electron-transfer reactions can often cause large displacement of molecular components [6,7,10,57]. Indeed, working with suitable systems, an endless sequence of cyclic molecular-level movements can in principle be performed making use of light-energy inputs without generating waste products [55,58].

Compared with chemical energy inputs, photonic energy has other advantages, besides the fundamental one of not generating waste products: (i) light can be switched on/off easily and rapidly; (ii) lasers provide the opportunity of working in very small space and very short time domains; (iii) photons, besides supplying the energy needed to make a machine work, can also be useful to "read" the state of the system and thus to control and monitor the operation of the machine. For all these reasons, photonic energy is extensively used to power artificial molecular machines.

Here we will briefly describe two examples: the first is based on a photoisomerization reaction, whereas the second relies on photoinduced electron-transfer processes.

\subsection{4}

\section{Threading-Dethreading of an Azobenzene-Based Pseudorotaxane}

Pseudorotaxanes are interesting in the context of molecular machinery, because the assembly-disassembly of the thread-like and macrocyclic components reminds one of the threading-dethreading of a needle. They can hardly be used to make unimolecular machines because of the chemical equilibrium between the components, but they represent good models for the development of rotaxane- and catenane-based systems.

An example of a pseudorotaxane exhibiting threading-dethreading motions based on a photoisomerization process is shown in Figure 1.15 [59]. The threadlike species trans-17, which contains a $\pi$-electron rich azobiphenoxy unit, and the $\pi$-electron-deficient macrocycle $18^{4+}$ self-assemble very efficiently to give a 
22 1 Artificial Photochemical Devices and Machines

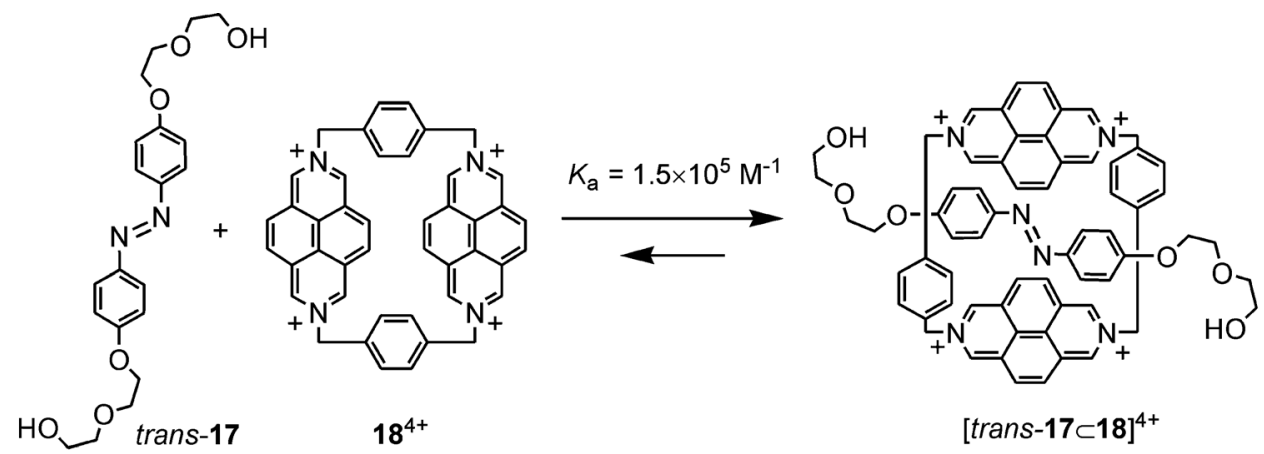

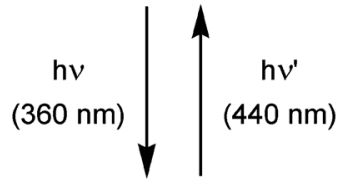<smiles>OCCOCCOc1ccc(N=Nc2ccc(OCCOCCO)cc2)cc1</smiles>

cis-17

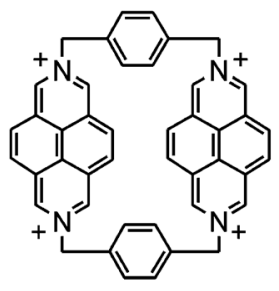

$$
K_{\mathrm{a}}=1 \times 10^{4} \mathrm{M}^{-1}
$$
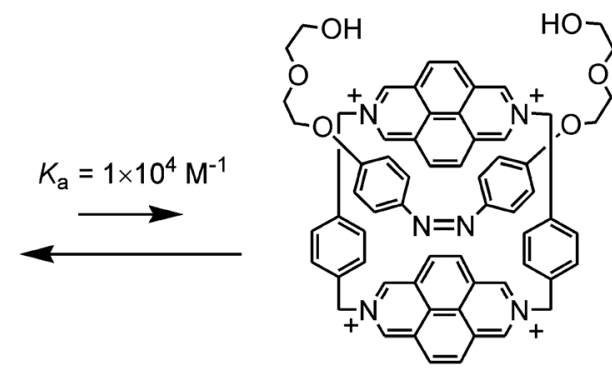

$[\operatorname{cis}-17 \subset 18]^{4+}$

Figure 1.15 Threading-dethreading of 17 and $18^{4+}$ as a consequence of the cis-trans photoisomerization of the azobenzene-type unit contained in the thread-like component 17 [48].

pseudorotaxane, stabilized by electron donor-acceptor interactions. The association constant, obtained by fluorescence titration in acetonitrile solution at room temperature, is $K_{\mathrm{a}}=(1.5 \pm 0.2) \times 10^{5} \mathrm{~L} \mathrm{~mol}^{-1}$. In the pseudorotaxane structure, the intense fluorescence characteristic of free $18^{4+}\left(\lambda_{\max }=434 \mathrm{~nm}\right.$, Figure 1.16) is completely quenched by the donor-acceptor interaction.

Irradiation of an acetonitrile solution containing $1.0 \times 10^{-4} \mathrm{~mol} \mathrm{~L}^{-1}$ trans-17 and $18^{4+}$ (ca. 80\% complexed species) with 365-nm light - almost exclusively absorbed by the trans-azobiphenoxy unit - causes strong absorption spectral changes, as expected for the well-known trans $\rightarrow$ cis photoisomerization of the azobenzene-type moiety. Such spectral changes are accompanied by a parallel increase in the intensity of the fluorescence band with $\lambda_{\max }=434 \mathrm{~nm}$ (Figure 1.16), characteristic of free $18^{4+}$ (see above). This behavior shows that photoisomerization is accompanied by dethreading (Figure 1.15), a result which is confirmed by the finding that the association constant of $18^{4+}$ with cis-17, $K_{\mathrm{a}}=(1.0 \pm 0.1) \times 10^{4} \mathrm{~L} \mathrm{~mol}^{-1}$, is much smaller than that with 


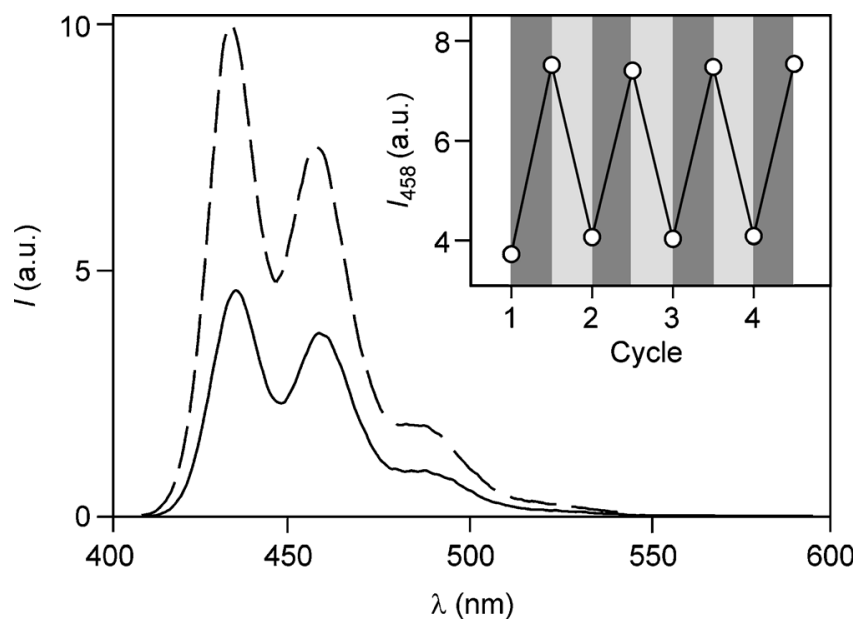

Figure 1.16 Fluorescence spectrum of an equimolar mixture $\left(1.0 \times 10^{-4} \mathrm{~mol} \mathrm{~L}^{-1}\right)$ of trans-17 and $18^{4+}$ in acetonitrile at room temperature (full line) and fluorescence spectrum of the same mixture after irradiation at $365 \mathrm{~nm}$ until a photostationary state is changes in intensity of the fluorescence associated with the free macrocyclic ring $18^{4+}$ upon consecutive trans $\rightarrow$ cis (irradiation at $365 \mathrm{~nm}$, dark areas) and cis trans $\rightarrow$ cis trans (irradiation at $436 \mathrm{~nm}$, light areas) photoisomerization cycles. Excitation is reached (dashed line). The inset shows the performed in an isosbestic point at $411 \mathrm{~nm}$ [59].

trans-17. On irradiation at $436 \mathrm{~nm}$ or by warming the solution in the dark, the trans isomer of $\mathbf{1 7}$ can be reformed. This process is accompanied by a parallel decrease in the fluorescence intensity at $\lambda_{\max }=434 \mathrm{~nm}$, indicating that the trans-17 species rethreads through the macrocycle $18^{4+}$.

Although this system is a rudimentary attempt towards the making of light-driven molecular machines, it should be noted that it exhibits a number of valuable features. First, threading-dethreading is controlled exclusively by light energy, without generation of waste products. Furthermore, owing to the reversibility of the photoisomerization process, the light-driven dethreading-rethreading cycle can be repeated at will (Figure 1.16, inset). Another relevant feature of this system is that it exhibits profound changes of a strong fluorescence signal.

\section{8 .5}

\section{Photoinduced Shuttling in Multicomponent Rotaxanes: a Light-Powered Nanomachine}

Rotaxanes are appealing systems for the construction of molecular machines because the mechanical binding of the macrocyclic host with its dumbbell-shaped substrate leaves the former free to displace itself along and/or around the latter without losing the system's integrity. Two interesting molecular motions can be envisaged in rotaxanes, namely (i) rotation of the macrocyclic ring around the thread-like portion of the dumbbell-shaped component and (ii) translation of the ring along the same portion. The molecular components of a rotaxane usually exhibit some kind of 
interaction originating from complementary chemical properties, which is also exploited in the template-directed synthesis of such systems. In rotaxanes containing two different recognition sites in their thread-like portion, it is possible to switch the position of the ring between these two "stations" by an external stimulus. Systems of this type, termed molecular shuttles [60], probably constitute the most common examples of artificial molecular machines. Interestingly, the dumbbell component of a molecular shuttle exerts a restriction on the ring motion in the three dimensions of space, similar to that imposed by the protein track for linear biomolecular motors kinesin and dynein [61].

On the basis of the experience gained with pseudorotaxane model systems [62], the rotaxane $19^{6+}$ (Figure 1.17) was specifically designed [63] to achieve photoinduced ring shuttling in solution. This compound has a modular structure; its ring component $\mathrm{R}$ is a $\pi$-electron-donating bis-p-phenylene [34]crown-10, whereas its dumbbell component is made of several covalently linked units. They are a $\mathrm{Ru}(\mathrm{II})$-polypyridine complex $\left(\mathrm{P}^{2+}\right)$, a $p$-terphenyl-type rigid spacer $(\mathrm{S})$, a 4,4'-bipyridinium $\left(\mathrm{A}_{1}{ }^{2+}\right)$ and a 3,3'-dimethyl-4,4'-bipyridinium $\left(\mathrm{A}_{2}{ }^{2+}\right) \pi$-electron-accepting stations and a

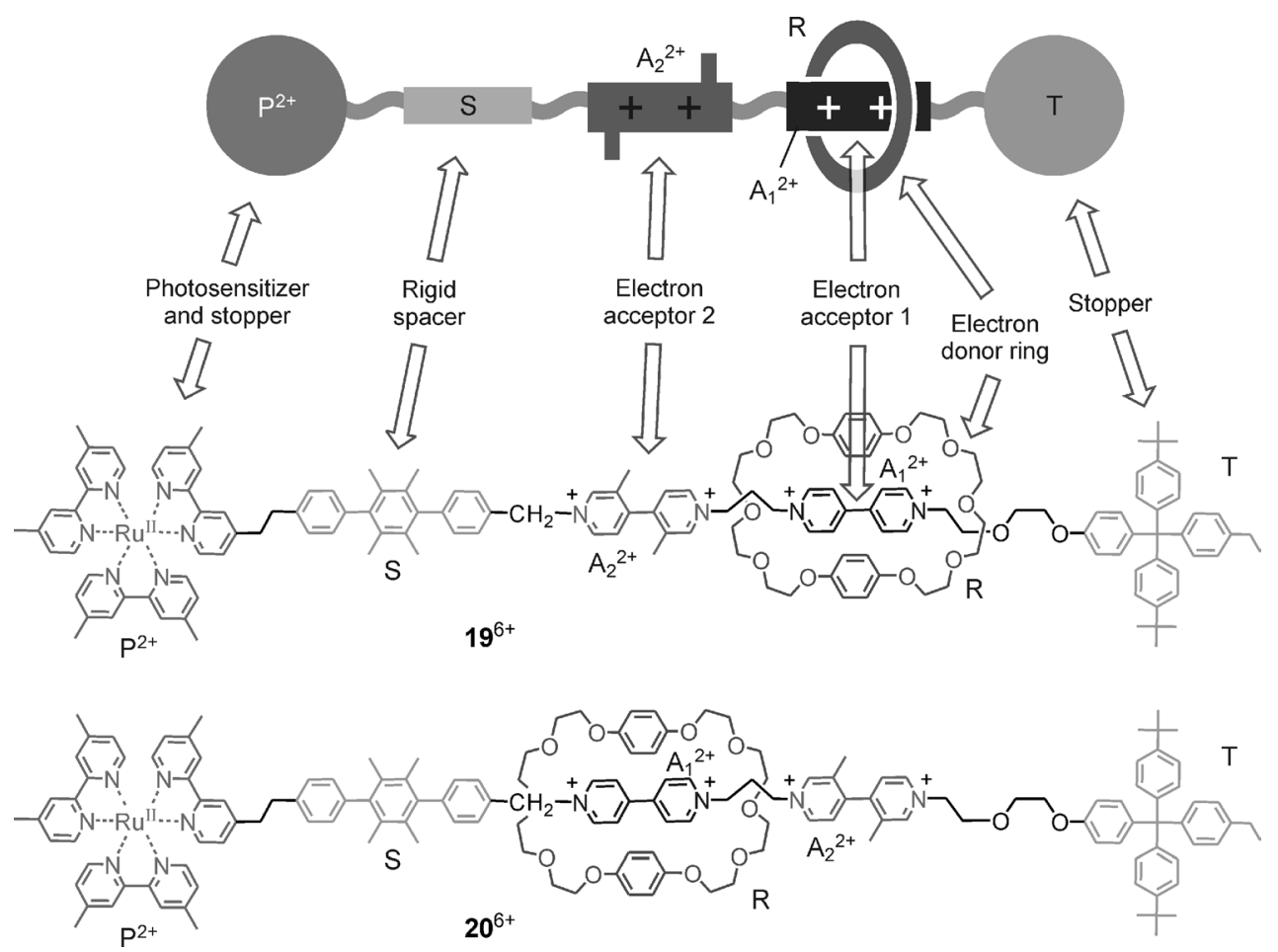

Figure 1.17 Structural formulas of multicomponent rotaxanes $19^{6+}[63]$ and $20^{6+}$ [66], designed to work as photochemically driven molecular shuttles. A cartoon representation of $19^{6+}$ is also shown. 
tetraarylmethane group as the terminal stopper $(\mathrm{T})$. The Ru-based unit plays the dual role of a light-fueled power station and a stopper, whereas the mechanical switch consists of the two electron-accepting stations and the electron-donating macrocycle. The stable translational isomer of rotaxane $\mathbf{1 9}^{\mathbf{6}+}$ is the one in which the R component encircles the $\mathrm{A}_{1}{ }^{2+}$ unit, in keeping with the fact that this station is a better electron acceptor than the other.

The strategy devised in order to obtain the photoinduced shuttling movement of the macrocycle between the two stations $\mathrm{A}_{1}{ }^{2+}$ and $\mathrm{A}_{2}{ }^{2+}$ is based on the following "four-stroke" synchronized sequence of electronic and nuclear processes (Figure 1.18):

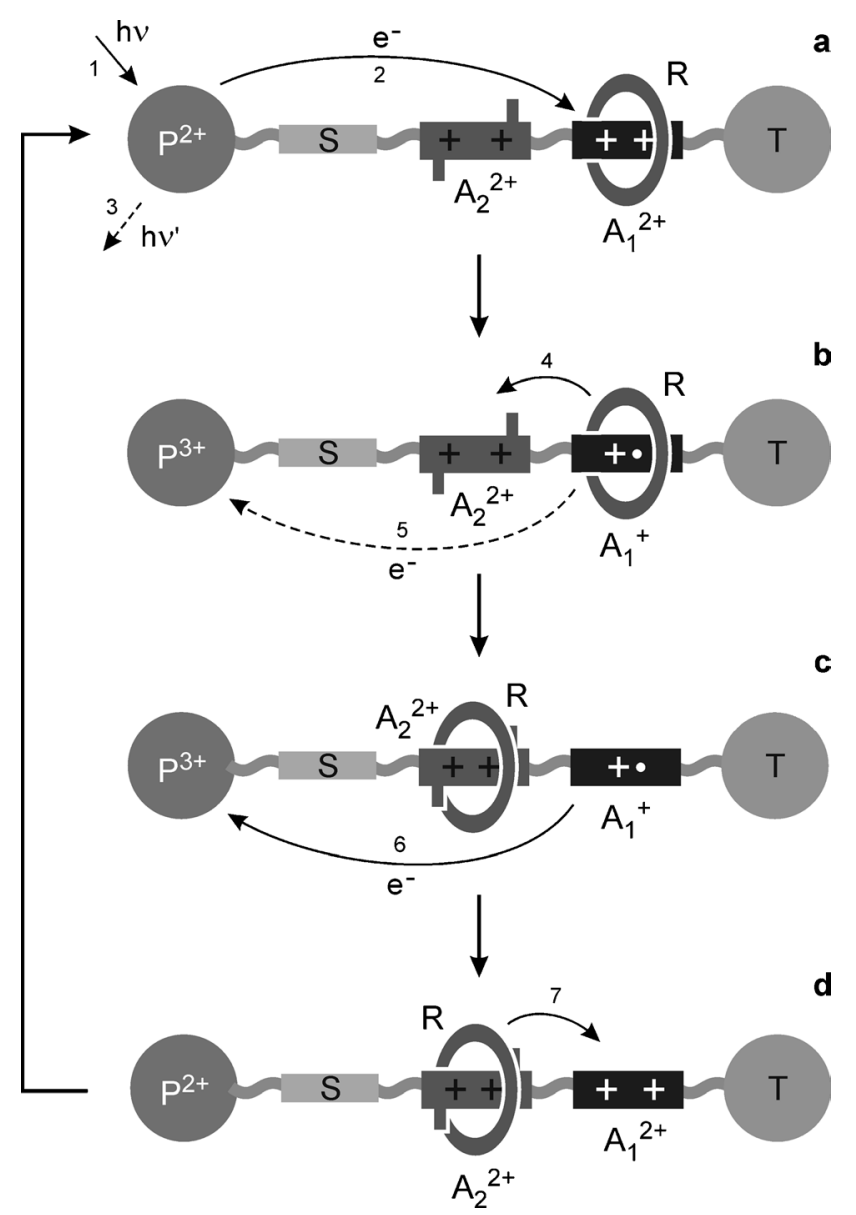

Figure 1.18 Schematic representation of the working mechanism of rotaxane $19^{6+}$ as an autonomous "four-stroke" molecular shuttle powered by visible light [64]. See Figure 1.17 for the legend for the cartoons. 
(a) Destabilization of the stable translational isomer: light excitation of the photoactive unit $\mathrm{P}^{2+}$ (process 1 ) is followed by the transfer of an electron from the excited state to the $\mathrm{A}_{1}{ }^{2+}$ station, which is encircled by the ring $\mathrm{R}$ (process 2 ), with the consequent "deactivation" of this station; such a photoinduced electron-transfer process competes with the intrinsic decay of the $\mathrm{P}^{2+}$ excited state (process 3 ).

(b) Ring displacement: the ring moves (process 4) for $1.3 \mathrm{~nm}$ from the reduced station $\mathrm{A}_{1}{ }^{+}$to $\mathrm{A}_{2}{ }^{2+}$, a step that is in competition with the back electron-transfer process from $\mathrm{A}_{1}^{+}$(still encircled by $\mathrm{R}$ ) to the oxidized unit $\mathrm{P}^{3+}$ (process 5).

(c) Electronic reset: a back electron-transfer process from the "free" reduced station $\mathrm{A}_{1}{ }^{+}$to the oxidized unit $\mathrm{P}^{3+}$ (process 6) restores the electron acceptor power to such a station. At this point the machine is reset and the ring has been "pumped" into an energetically higher state.

(d) Nuclear reset: as a consequence of the electronic reset, thermally activated back movement of the ring from $\mathrm{A}_{2}{ }^{2+}$ to $\mathrm{A}_{1}{ }^{2+}$ takes place (process 7).

Steady-state and time-resolved spectroscopic experiments together with electrochemical measurements in acetonitrile solution showed [64] that the absorption of a visible photon by $19^{6+}$ can cause the occurrence of a forward and back ring movement, that is, a full mechanical cycle according to the mechanism illustrated in Figure 1.18 [65]. It was estimated that the fraction of the excited-state energy used for the motion of the ring amounts to $\sim 10 \%$ and the system can generate a mechanical power of about $3 \times 10^{-17} \mathrm{~W}$ per molecule. The somewhat disappointing quantum efficiency for ring shuttling $\left(2 \%\right.$ at $\left.30^{\circ} \mathrm{C}\right)$ is compensated for by the fact that the investigated system gathers together the following features: (i) it is powered by visible light (in other words, sunlight); (ii) it exhibits autonomous behavior, like motor proteins; (iii) it does not generate waste products; (iv) its operation can rely only on intramolecular processes, allowing in principle operation at the single-molecule level; (v) it can be driven at a frequency of about $1 \mathrm{kHz}$; (vi) it works in mild environmental conditions (i.e. fluid solution at ambient temperature); and (vii) it is stable for at least $10^{3}$ cycles.

The molecular shuttle $19^{6+}$ can also be operated, with a higher quantum yield, by a sacrificial mechanism [63] based on the participation of external reducing (triethanolamine) and oxidizing (dioxygen) species and by an intermolecular mechanism [64] involving the kinetic assistance of an external electron relay (phenothiazine), which is not consumed. However, operation by the sacrificial mechanism does not afford an autonomous behavior and leads to consumption of chemical fuels and formation of waste products. On the other hand, the assistance by an electron relay affords autonomous operation in which only photons are consumed, but the mechanism is no longer based solely on intra-rotaxane processes.

Owing to its modular design, the rotaxane $19^{6+}$ is amenable to structural modification in an attempt to improve its performance as a light-driven molecular shuttle. For instance, the rotaxane $\mathbf{2 0}{ }^{6+}$ (Figure 1.17), which differs from $19^{6+}$ only in the exchange of the position of the two electron-accepting stations along the dumbbell-shaped component, has been recently synthesized and its photochemical 
properties investigated [66]. It has been found that the shorter distance of the electron-transfer photosensitizer $\mathrm{P}^{2+}$ to the better $\left(\mathrm{A}_{1}{ }^{2+}\right)$ of the two electron acceptors in $20^{6+}$ results in an increase in the rate - and hence the efficiency - of the photoinduced electron-transfer step compared with $19^{6+}$. The rate of the back electron transfer, however, also increases. As a consequence, such a second-generation molecular shuttle performs better than $\mathbf{1 9}^{\mathbf{6}+}$ in a sacrificial mechanism, but much worse when it is powered by visible light (e.g. sunlight) alone. Another interesting difference between these two parent rotaxanes lies in the fact that the macrocyclic ring $\mathrm{R}$, which initially surrounds the $\mathrm{A}_{1}{ }^{2+}$ station, moves in opposite directions upon light excitation, i.e. towards the photosensitizer $\mathrm{P}^{2+}$ in $19^{6+}$ and towards the stopper $\mathrm{T}$ in $20^{6+}$.

This study shows that the structural and functional integration of different molecular subunits in a multicomponent structure is a powerful strategy for constructing nanoscale machines [67]. Nevertheless, the molecular shuttle $19^{6+}$ in its present form could not perform a net mechanical work in a full cycle of operation [68] (as for any reversible molecular shuttle, the work done in the "forward" stroke would be cancelled by the "backward" stroke) [69]. To reach this goal, a more advanced design of the molecular machine and/or a better engineering of its operating environment (e.g. a surface or a membrane) are required [6].

\section{9}

\section{Conclusion}

One of the most interesting aspects of supramolecular (multicomponent) systems is their interaction with light. The systems described here show that, in the frame of research on supramolecular photochemistry, the design and construction of nanoscale devices capable of performing useful light-induced functions can indeed be attempted.

The potential applications of photochemical molecular devices and machines are various - from energy conversion to sensoring and catalysis - and, to a large extent, still unpredictable. As research in the area is progressing, two interesting kinds of unconventional applications of these systems begin to emerge: (i) their behavior can be exploited for processing information at the molecular level [70] and, in the long run, for the construction of chemical computers [71]; and (ii) their mechanical features can be utilized for transportation of nano-objects, mechanical gating of molecular-level channels and nanorobotics [72].

However, it should be noted that the species described here, as most multicomponent systems developed so far, operate in solution, that is, in an incoherent fashion and without control of spatial positioning. Although the solution studies are of fundamental importance to understand their operation mechanisms and for some use (e.g. drug delivery), it seems reasonable that before such systems can find applications in many fields of technology, they will have to be interfaced with the macroscopic world by ordering them in some way. The next generation of multicomponent molecular species will need to be organized so that they can behave 
coherently and can be addressed in space. Viable possibilities include deposition on surfaces, incorporation into polymers, organization at interfaces or immobilization into membranes or porous materials. Recent achievements in this direction [73-76] suggest that useful devices based on functional (supra)molecular systems could be obtained in the not too distant future.

Apart from foreseeable applications related to the development of nanotechnology, investigations on photochemical molecular devices and machines are important to increase the basic understanding of photoinduced reactions and other important processes such as self-assembly, and also to develop reliable theoretical models. This research also has the important merit of stimulating the ingenuity of chemists, thereby instilling new life into chemistry as a scientific discipline.

\section{Acknowledgments}

Financial support from the European Union (STREP "Biomach" NMP2-CT2003-505487), MIUR (PRIN 2006034123-001), Regione Emilia-Romagna (NANOFABER) and the University of Bologna is gratefully acknowledged.

\section{References}

1 Hader, D.-P. and Tevini, M. (1987) General Photobiology, Pergamon Press, Oxford.

2 Nalwa, H.S. (ed.) (2003) Handbook of Photochemistry and Photobiology, American Scientific Publishers, Stevenson Ranch, CA, vols. 1-4.

3 Joachim, C. and Launay, J.P. (1984) Nouv. J. Chem., 8, 723.

4 Balzani, V., Moggi, L. and Scandola, F. (1987) Supramolecular Photochemistry (ed. V. Balzani), Reidel, Dordrecht, p. 1.

5 Lehn, J.-M. (1988) Angew. Chem. Int. Ed., 27, 89.

6 Balzani, V., Credi, A. and Venturi, M. (2003) Molecular Devices and Machines - a Journey into the Nano World, Wiley-VCH, Weinheim.

7 Balzani, V., Credi, A., Raymo, F.M. and Stoddart, J.F. (2000) Angew. Chem. Int. Ed., 39, 3348.

8 Kay, E.R., Leigh, D.A. and Zerbetto, F. (2007) Angew. Chem. Int. Ed., 46, 72.

9 Gilbert, A. and Baggott, J. (1991) Essentials of Molecular Photochemistry, Blackwell Science, London.
10 Balzani, V. and Scandola, F. (1991) Supramolecular Photochemistry, Ellis Horwood, Chichester.

11 Balzani, V. (ed.) (2001) Electron Transfer in Chemistry, Wiley-VCH, Weinheim, vols. 1-5.

12 Nalwa, H.S. (ed.) (2003) Handbook of Photochemistry and Photobiology, American Scientific Publishers, Stevenson Ranch, CA, vols. 1-4.

13 Michl, J. (2006) in Handbook of Photochemistry, 3rd edn (eds M. Montalti, A. Credi, L. Prodi and M.T. Gandolfi) CCR, Taylor and Francis, New York. p. 1.

14 Balzani, V. (2006) in Handbook of Photochemistry 3rd edn (eds M. Montalti, A. Credi, L. Prodi and M.T. Gandolfi) CCR, Taylor and Francis, New York, p. 49.

15 Lakowicz, J.R. (2006) Principles of Fluorescence Spectroscopy, 3rd edn Springer, Singapore.

16 Montalti M., Credi A., Prodi L. and Gandolfi M.T. (eds) (2006) Handbook of Photochemistry, 3rd edn CCR, Taylor and Francis, New York. 
17 Balzani, V., Bolletta, F., Gandolfi, M.T. and Maestri, M. (1978) Top. Curr. Chem., $75,1$.

18 Adv. Chem. Phys. (1999). pp. 106-107 special volumes (eds M. Bixon, J. Jortner) on Electron Transfer: from Isolated Molecules to Biomolecules.

19 May, V. and Kühn, O. (2000) Charge and Energy Transfer Dynamics in Molecular Systems, Wiley-VCH, Weinheim.

20 Gray, H.B. and Winkler, J.R. (2003) Q. Rev. Biophys., 36, 341.

21 Indelli, M.T., Bignozzi, C.A., Harriman, A., Schoonover, J.R. and Scandola, F. (1994) J. Am. Chem. Soc., 116, 3768.

22 Indelli, M.T., Chiorboli, C., Flamigni, L., De Cola, L. and Scandola, F. (2007) Inorg. Chem, 46, 5630.

23 Juris, A., Balzani, V., Barigelletti, F., Campagna, S., Belser, P. and von Zelewsky, A. (1988) Coord. Chem. Rev., 84, 85.

24 Balzani, V. and Scandola, F. (1996) Comprehensive Supramolecular Chemistry (eds J.L. Atwood, J.E.D. Davies, D.D. MacNicol and F. Vögtle), Pergamon Press, Oxford, vol. 10, p. 687.

25 Flamigni, L., Baranoff, E., Collin, J.-P. and Sauvage, J.-P. (2006) Chem. Eur. J., 12, 6592.

26 Th. Förster, Discuss. Faraday Soc., 1959, 27, 7. Note that in this paper there is a misprint since in Eq. (29) $\pi^{6}$ is used instead of $\pi^{5}$. See (a) Förster, Th. (1965) Modern Quantum Chemistry (ed. O. Sinanoğlu) Academic Press New York Part III: Action of Light and Organic Crystals,93. (b) Barigelletti, F. and Flamigni, L. (2000) Chem. Soc. Rev., 29, 1. (c) Scholes, G.D. (2003) Annu. Rev. Phys. Chem., 54, 57.

27 Welter, S., Salluce, N., Belser, P., Groeneveld, M. and De Cola, L. (2005) Coord. Chem. Rev., 249, 1360.

28 Dexter, D.L. (1953) J. Chem. Phys., 21, 836.

29 Schlicke, B., Belser, P., De Cola, L., Sabbioni, E. and Balzani, V. (1999) J. Am. Chem. Soc., 121, 4207.

30 D'Aleo, A., Welter, S., Cecchetto, E. and De Cola, L. (2005) Pure Appl. Chem., 77.1035.
31 Welter, S., Lafolet, F., Cecchetto, E., Vergeer, F. and De Cola, L. (2005) ChemPhysChem, 6, 2417.

32 Liddell, P.A., Kodis, G., Andréasson, J., de la Garza, L., Bandyopadhyay, S., Mitchell, R.H., Moore, T.A., Moore, A.L. and Gust, D. (2004) J. Am. Chem. Soc., 126, 4803.

33 Balzani, V., Credi, A. and Venturi, M. (2002) Proc. Natl. Acad. Sci. USA, 99, 4814.

34 Ishow, E., Credi, A., Balzani, V., Spadola, F. and Mandolini, L. (1999) Chem. Eur. J., 5, 984.

35 (a) Kolchinski, A.G., Busch, D.H. and Alcock, N.W. (1995) J. Chem. Soc., Chem. Commun., 1289. (b) Ashton, P.R., Campbell, P.J., Chrystal, E.J.T., Glink, P.T., Menzer, S., Philp, D., Spencer, N., Stoddart, J.F., Tasker, P.A. and Williams, D.J. 1865 Angew. Chem. Int. Ed., 1995, 34,

36 Clemente-León, M., Pasquini, C., HebbeViton, V., Lacour, J., Dalla Cort, A. and Credi, A. (2006) Eur. J. Org. Chem., 105.

37 Ballardini, R., Balzani, V., Clemente-Leon, M., Credi, A., Gandolfi, M.T., Ishow, E., Perkins, J., Stoddart, J.F., Tseng, H.-R. and Wenger, S. (2002) J. Am. Chem. Soc., 124, 12786.

38 Ferrer, B., Rogez, G., Credi, A., Ballardini, R., Gandolfi, M.T., Balzani, V., Liu, Y., Tseng, H.-R. and Stoddart, J.F. (2006) Proc. Natl. Acad. Sci. USA, 103, 18411.

39 Rogez, G., Ferrer Ribera, B., Credi, A., Ballardini, R., Gandolfi, M.T., Balzani, V., Liu, Y., Northrop, B.H. and Stoddart, J.F. (2007) J. Am. Chem. Soc., 129, 4633.

40 Balzani, V., Credi, A. and Venturi, M. (1997) Curr. Opin. Chem. Biol., 1, 506.

41 Alpha, B., Balzani, V., Lehn, J.-M., Perathoner, S. and Sabbatini, N. (1987) Angew. Chem. Int. Ed. Engl., 26, 1266.

42 Bünzli, J.-C.G. and Piguet, C. (2005) Chem. Soc. Rev., 34.1048.

43 Blankenship, R.E. (2002) Molecular Mechanism of Photosynthesis, Blackwell Science, Oxford.

44 Balzani, V., Ceroni, P., Gestermann, S., Kauffmann, C., Gorka, M. and Vögtle, F. (2000) Chem. Commun., 853. 
45 Oar, M.A., Dichtel, W.R., Serin, J.M., Fréchet, J.M.J., Rogers, J.E., Slagle, J.E., Fleitz, P.A., Tan, L.-S., Ohulchanskyy, T.Y. and Prasad, P.N. (2006) J. Am. Chem. Soc., 18, 3682.

46 Yan, X., Goodson, T., III Imaoka, T. and Yamamoto, K. (2005) J. Phys. Chem. B, 109, 9321.

47 Hecht, S. and Fréchet, J.M.J. (2001) Angew. Chem. Int. Ed., 40, 75.

48 Pleovets, M., Vögtle, F., De Cola, L. and Balzani, V. (1999) New J. Chem., 23, 63.

49 Balzani, V., Bergamini, G., Marchioni, F. and Ceroni, P. (2006) Coord. Chem. Rev., 250, 1254.

50 The dendrimer branches protect the excited state of the core also from quenching by other species: Vögtle, F., Plevoets, M., Nieger, M., Azzellini, G.C., Credi, A., De Cola, L., De Marchis, V., Venturi, M. and Balzani, V. (1999) J. Am. Chem. Soc., 121, 6290.

51 Goodsell, D.S. (2004) Bionanotechnology Lessons from Nature, Wiley, Hoboken, NJ.

52 Jones, R.A.L. (2004) Soft Machines, Nanotechnology and Life, Oxford University Press, Oxford.

53 (a) Feynman, R.P. (1960) Eng. Sci., 23, 22.

(b) Feynman, R.P. (1960) Saturday Rev., 43, 45. See alsohttp://www.feynmanonline. com.

54 See, e.g.: (a) Balzani, V., Credi, A., Langford, S.J., Raymo, F.M., Stoddart, J.F. and Venturi, M. (2000) J. Am. Chem. Soc., 122, 3542. (b) Jimenez-Molero, M.C., DietrichBucheker, C. and Sauvage, J.-P. (2002) Chem. Eur. J., 8, 1456. (c) Badji,ć J.D., Balzani, V., Credi, A., Silvi, S. and Stoddart, J.F. (2004) Science, 303, 1845. (d) Leigh, D.A., Lusby, P.J., Slawin, A.M.Z. and Walker, D.B. (2005) Chem. Commun., 4919

55 Ballardini, R., Balzani, V., Credi, A., Gandolfi, M.T. and Venturi, M. (2001) Acc. Chem. Res., 34, 445.

56 See, e.g.: (a) Shinkai, S., Nakaji, T., Ogawa, T., Shigematsu, K. and Manabe, O. (1981) J. Am. Chem. Soc., 103, 111. (b) Irie, M. and Kato, M. (1985) J. Am. Chem. Soc., 107, 1024. (c) van Delden, R.A., Koumura, N.,
Schoevaars, A., Meetsma, A. and Feringa, B.L. (2003) Org. Biomol. Chem., 1, 33.

(d) Leigh, D.A., Wong, J.K.Y., Dehez, F. and Zerbetto, F. (2003) Nature, 424, 174. (e) Qu, D.-H., Wang, Q.-C. and Tian, H. (2005) Angew. Chem. Int. Ed., 44, 5296. (f) Muraoka, T., Kinbara, K. and Aida, T. 2006 Nature, 440, 512

57 Credi, A. (2006) Aust. J. Chem., 59, 157.

58 Ballardini, R., Balzani, V., Credi, A., Gandolfi, M.T. and Venturi, M. (2001) Int. J. Photoenergy, 3, 63.

59 Balzani, V., Credi, A., Marchioni, F. and Stoddart, J.F. (2001) Chem. Commun., 1861.

60 Bissell, A., Córdova, E., Kaifer, A.E. and Stoddart, J.F. (1994) Nature, 369, 133.

61 Schliwa M. (ed.) (2003) Molecular Motors, Wiley-VCH, Weinheim.

62 (a) Ballardini, R., Balzani, V., Gandolfi, M.T., Prodi, L., Venturi, M., Philp, D., Ricketts, H.G. and Stoddart, J.F. (1993) Angew. Chem. Int. Ed., 32, 1301. (b) Ashton, P.R., Ballardini, R., Balzani, V., Constable, E.C., Credi, A., Kocian, O., Langford, S.J., Preece, J.A., Prodi, L., Schofield, E.R., Spencer, N., Stoddart, J.F. and Wenger, S. (1998) Chem. Eur. J., 4, 2413. (c) Ashton, P.R., Balzani, V., Kocian, O., Prodi, L., Spencer, N. and Stoddart, J.F. 1998 J. Am. Chem. Soc., 120, 11190

63 Ashton, P.R., Ballardini, R., Balzani, V., Credi, A., Dress, R., Ishow, E., Kleverlaan, C.J., Kocian, O., Preece, J.A., Spencer, N., Stoddart, J.F., Venturi, M. and Wenger, S. 2000 Chem. Eur. J., 6, 3558.

64 Balzani, V., Clemente-León, M., Credi, A., Ferrer, B., Venturi, M., Flood, A.H. and Stoddart, J.F. (2006) Proc. Natl. Acad. Sci. USA, 103, 1178.

65 For a related example of a photochemically driven molecular shuttle, see: Brouwer, A.M., Frochot, C., Gatti, F.G., Leigh, D.A., Mottier, L., Paolucci, F., Roffia, S. and Wurpel, G.W.H. (2001) Science, 291, 2124.

66 Balzani, V., Clemente-León, M., Credi, A., Semeraro, M., Venturi, M., Tseng, H.-R., Wenger, S., Saha, S. and Stoddart, J.F. (2006) Aust. J. Chem., 59, 193. 
67 Balzani, V., Credi, A., Silvi, S. and Venturi, M. (2006) Chem. Soc. Rev., 35, 1135.

68 Kay, E.R. and Leigh, D.A. (2006) Nature, 440, 286.

69 Chatterjee, M.N., Kay, E.R. and Leigh, D.A. (2006) J. Am. Chem. Soc., 128, 4058.

70 For a representative recent example, see: Margulies, D., Felder, C.E., Melman, G. and Shanzer, A. (2007) J. Am. Chem. Soc., 129, 347.

71 (a) Rouvray, D. (2000) Chem. Br., 36 (12), 46. (b) Ball, P. (2000) Nature, 406, 118.

72 Requicha, A.A.G. (2003) Proc. IEEE, 91, 1922.
73 Berná J., Leigh, D.A., Lubomska, M., Mendoza, S.M., Pérez, E.M., Rudolf, P., Teobaldi, G. and Zerbetto, F. (2005) Nature Mater., 4, 704.

74 Kocer, A., Walko, M., Meijberg, W. and Feringa, B.L. (2005) Science, 309, 755.

75 de Silva, A.P., James, M.R., Mckinney, B.O.F., Pears, D.A. and Weir, S.M. (2006) Nature Mater., 5, 787.

76 Bhosale, S., Sisson, A.L., Talukdar, P., Furstenberg, A., Banerji, N., Vauthey, E., Bollot, G., Mareda, J., Roger, C., Würthner, F., Sakai, N. and Matile, S. (2006) Science, 313, 84. 
